

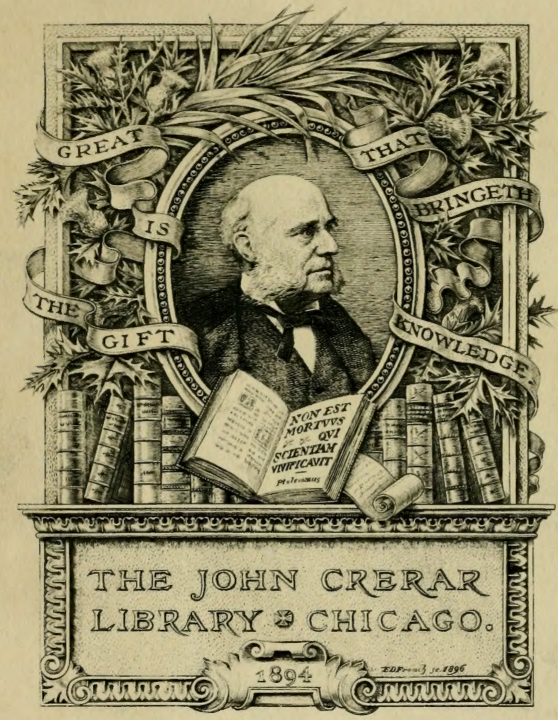




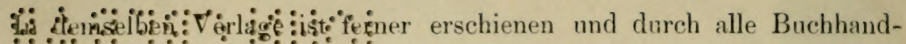

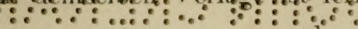

$\therefore \because \therefore$ : $\because \cdots:$ lungen zu beziehen:

FAUNA AUSTRIACA.

\title{
Die Käfer.
}

Nach der analytischen Methode bearbeitet ron

Dr. Ludwig Redtenbacher.

Zweite, gänzlich umgearbeitete, mit mehreren Hunderten von Arten und mit der Charakteristik sämmtlicher europäischen Käfergattungen vermehrte Auflage. gr. 8. br. Preis: 14 fl. $20 \mathrm{kr}$. Österr. Währ.

Die

\section{EUROPÄISCHE HEMIPTERA. (RHYNCHOTA HETEROPTERA.)}

\author{
Nach \\ der analytischen llethode bearbeitet von \\ Dr. Franz aver Fieber. \\ gr. 8. br Preis : complet fl. 6.-- Österr. Währung.

\section{F A UNA A USTRI A CA.} \\ Die Fliegen. (Diptera.)
}

Nach der analytischen Methode bearbeitet von

\section{Dr. J. Rudolph Schiner.}

Mit der Charakteristik sämmtlicher europäischer Gattungen, der Beschreibung aller in Deutschland vorkommenden Arten und dem Verzeichnisse der beschriebenen europäischen Arten.

Fünf Hefte. Mit zwei Steindrucktafeln. gr. 8. br. Preis à 1 fl. 50 kr. Ö. W. (Wird fortgesetzt.) 


\section{Die Europäischen}

\section{F O R M I C I D E N.}

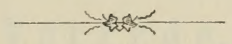

Nach der

analytischen Methode bearbeitet

von

Dr. Gustav L. Mayr.

Mit einer lithographirten Tatel.

\section{Wien.}

Druck und Verlag von Carl Gerold's Sohn.

\section{1.}




$$
\begin{aligned}
& Q L \\
& 568 \\
& \text { F } \\
& \text { M29 }
\end{aligned}
$$

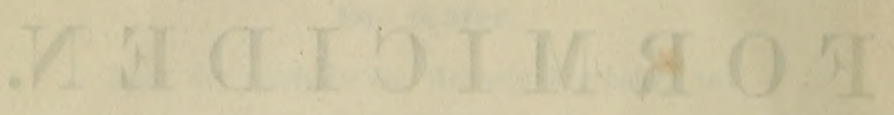




\section{Vorrede.}

Die Forschungen im Gebiete der Myrmecologie haben sich seit der Publication meiner "Formicina austriaca" bedeutend vermehrt, es wurde Vieles gesichtet, aber auch Manches verwirrt, es wurden mehrere neue Arten entdeckt, doch fehlt es bis jetzt noch an einer durchgreifend logischen Charakteristik der Genera. Ich habe mich bemüht, eine scharfe Charakterisirung der Gattungen der europäischen Ameisen bei Berücksichtigung der exotischen Formiciden in vorliegender Arbeit auszuführen.

Das wichtigste in neuester Zeit über die Ameisen publicirte Werk ist Smith's Catalogue of Hymenopterous Insects, Formicidae, 1858, eine Zusammenstellung aller beschriebenen Arten der ganzen Erde, ein Grundwerk für jede weitere Forschung, besonders für die exotischen Ameisen. Die vorhandenen Fehler wird der Fachmann, der die grossen Schwierigkeiten einer solchen Bearbeitung kennt, mit Nachsicht beurtheilen. Herr Smith veröffentlichte ferner eine Revision of an Essay on the British Formicidae, in welcher wenige Aufklärungen zu finden sind. Dr. Nylander bereicherte die Myrmecologie mit einer Synopsis des Formicides de France et d'Algérie. Die von diesem Autor in Russland publicirten Arbeiten zeigten durchwegs, dass ihr Verfasser viele Mühe und ausdauernden Fleiss darauf verwendet hatte, während die in Frankreich veröffentlichte oben angeführte Abhandlung wohl nur kurze Zeit unter der diessmal flüchtigen Hand des Autors gelegen ist. Förster's Beschreibungen von algierischen Ameisen in den Verhandlungen des naturhistorischen Vereines der Rheinlande im VII. Bande wurden leider von Dr. Nylander nicht benützt, obschon ihm dieselben dem Namen

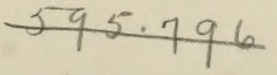


nach bekannt waren, da er aus meiner Abhandlung über die österreichischen, deutschen und italienischen Ameisen die Gattung Cata glyphis citirt, welche in obigen Beschreibungen aufgestellt ist. Eine kleine, aber mit vielem Fleisse gearbeitete Abhandlung ist von Herrn Sanitätsrath $\mathrm{R}$ og e r über die Ameisen der Mittelmeerländer veröffentlicht worden, welche Arbeit interessante und schätzenswerthe Aufklärungen über manche zweifelhafte Arten bringt. Ferner wurden von Herrn Dr. Roger kritische Bemerkungen über Formica capsincola Schill. geliefert. Prof. Gredler hat im VIII. Programme des Gymnasiums zu Bozen die Ameisen Tirol's und ich Ungarn's Ameisen im Programme der Oberrealschule zu Pest für das Schuljahr 1856/57 mit dem besonderen Zwecke, den Anfänger in das Studium der Ameisen-Familie einzuführen, veröffentlicht. Professor Schenck gab eine „Systematische Eintheilung der nassauischen Ameisen nach Mayr, welche nichts Neues bringt. In dem Werke Dr. Rosenhauer's: „Die Thiere Andalusiens," findet sich eine Aufzählung von mir determinirter Ameisen, welche erst durch Dr. Rog er's Beiträge der Ameisen der Mittelmeerländer, sowie durch diese meine vorliegende Arbeit vervollständigt wird. Herr L. D u fou $\mathrm{r}$ beschrieb in den Annales de la Société entomologique de France V. pag. 60 ein neues Genus Micromyrma, deren Beschreibung und ausnehmend schlechte Abbildung so viele Zweifel übrig lassen, dass ich die Aufnahme dieser Gattung in die Reihe der europäischen Ameisen indessen nicht rechtfertigen kann, umsomehr, da mir ein Original-Exemplar derselben, welche ich übrigens für ein echtes Tapinoma (vielleicht sehr kleines T. erraticum) halte, vor der vollständigen Untersuchung zu Grunde ging. Eine Aufzählung von Ameisen aus Ungarn, dem Banate und der Banater Militärgrenze in den Verhandlungen der k. k. zoologisch-botanischen Gesellschaft, sowie ein Beitrag zur Ameisen - Fauna Russlands in der Stettiner entomologischen Zeitung wurden von mir publicirt. Eine Aufzählung der auf dem Mont d'Or von Dr. Nylander beobachteten Ameisen (Bulletin Soc. ent. 1856 pag. LXXVIII) liefert nichts Interessantes. In allerneuester Zeit veröffentlichte Herr $\mathrm{M}$ einert eme Abhandlung: „Bidrag til de danske Myrers Naturhistorie, kgl. dansk. Videnkab. Selskabs Skrifter, 5te Raekke, naturv. Afd., V. Bind 1860," welche ich leider nicht zur Ansicht erhalten konnte.

Es sei mir an diesem Orte vergönnt, mich gegen die von Dr. Gerstäcker im Berichte über die wissenschaftlichen Leistungen im Gebiete der Entomologie während des Jahres 1856, p. 122, gegen 
mich und Dr. Nylander erhobene Anklage, dass wir Leach's Descriptions of thirkeen Species of Formica and three Species of Culex found in the Environs of Nice in Vigors Zoological Journal II, 1826, nicht benützt haben, zu vertheidigen. Diese Beschreibungen sind so enorm schlecht, dass man bei manchen Arten nicht einmal die Subfamilie zu eruiren im Stande ist, geschweige erst die Gattung oder Art bestimmen zu können, so dass ich es für zweckmässig hielt und noch halte, eine so unwissenschaftliche Arbeit, welche vielleicht selbst im vorigen Jahrhunderte unberücksichtigt geblieben wäre, ganz zu übergehen. Einige Losana'sche Arten, welche durchaus räthselhaft geblieben sind, habe ich in vorliegender Arbeit übergangen.

Auf die vorliegende Bearbeitung der europäischen Ameisen übergehend, erlaube ich mir, über dieselbe einige Bemerkungen zu machen. Es war mein Streben, solche Gattungs-Charaktere bei der analytischen Tabelle zu benützen, welche mittelst einer guten Loupe mit Leichtigkeit gesehen werden können, so dass das manchem Hymenopterologen noch ziemlich verhasste Mikroskop entbehrt werden kann. Ich habe hiedurch auch den Beweis geliefert, dass die Mundtheile nicht so unentbehrlich zur Charakteristik der Gattungen sind und dass das ganze Chitinskelet hinreichende Merkmale zur Unterscheidung der Gattungen liefert. Sehr eigenthümlich ist das Verhalten der Männchen mancher Gattungen, indem sich oft die Arten e in e r Gattung schwer unterscheiden lassen, während die Weibchen und Arbeiter leicht zu unterscheiden sind; hingegen unterscheiden sich die Männchen generisch sehr leicht von einander, während bei den Weibchen und Arbeitern dann das umgekehrte Verhältniss stattfindet.

Um die Synonymie in vorliegender Arbeit nicht zu sehr und unnöthigerweise anzuhäufen, habe ich alle jene Citate, welche bereits in meinem Werke: „Formicina austriaca” vorkommen, ausgelassen, mit Ausnahme des Citates der ersten Beschreibung einer Art. (Gredler's Ameisen Tirol's habe ich bei den einzelnen Arten nicht citirt, da sie sich ganz auf meine obgenannte Abhandlung fusst, es wurde nur die Beschreibung einer neuen Art aufgenommen.)

Die 37 Figuren auf beifolgender Tafel sind sämmtlich von mir mit der Camera lucida gezeichnet; bei deren Anfertigung war mir weniger an einem gleichförmigen Grössen-Verhältniss, als insbesondere an grosser Genauigkeit gelegen.

Ich habe es vermieden, im speciellen Theile die Verbreitung der Arten genauer anzugeben, um die Uebersichtlichkeit beim Bestimmen 
nicht zu stören; ein eigenes Capitel im allgemeinen Theile gibt den nöthigen Nachweis über die Verbreitung der Arten.

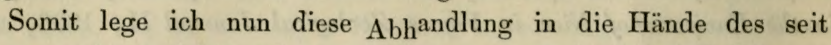
mehreren Jahren nicht mehr so kleinen myrmecologischen Publicums mit der Hoffnung, einen Beitrag zur Kenntniss der Formiciden geliefert zu haben. So eben nach Abschluss dieser Arbeit mit den exotischen Ameisen beschäftigt, werde ich jedem Entomologen zu Dank verpflichtet sein, der mich mit Zusendung des betreffenden Materiales unterstützt.

Pest, im April 1861.

Dr. G. Mayr. 


\section{Einleitung.}

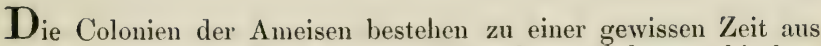
dreierlei Individuen, den W eibchen, den Männchen und den geschlechtslosen Arbeitern, sowie bei einer europäischen Gattung noch ausserdem aus den ebenfalls geschlechtslosen Soldaten.

Der Körper der Ameisen ist aus folgenden scharf getremnten Theilen zusammengesetzt: dem Kopfe, Thorax, Hinterleib, den Beinen und bei den Weibchen und Männchen noch aus den Flügeh.

\section{Ko p f.}

Der an der Oberseite gewölbte, an der Unterseite mehr oder weniger flache Kopf hat vorne und unten eine grosse Mundöffinung, welche von den Mundtheilen verschlossen wird. Die obere Begrenzung dieser Oeffnung bildet der durch eine Furche von den übrigen Kopftheilen abgegrenzte Clypeus, hinter welchem die Stimleisten mit den darunter entspringenden Fühlern liegen. Zwischen den Stirnleisten hinter dem Clypeus ist das meist deutliche Stirnfeld eingedrückt, und hinter diesem zieht sich sehr häufig eine mittlere Längslinie, die Stirnrinne, durch die Stirn bis zu den häufig vorhandenen Punctaugen am Scheitel. Die nur sehr selten fehlenden Netzaugen sind seitlich am Kopfe angebracht, vor denselben liegen bis zu den Mundtheilen die am Oberkiefergelenke ausgerandeten Wangen. Die Unterseite des Kopfes wird Kehle genannt und endet rückwärts mit dem Hinterhauptloche.

Die Mundtheile bestehen aus den paarigen starken Oberkiefern, aus der Oberlippe, welche die Mundöfthung vorne öfthen und schliessen kann, aus den die Mundöffinung unten abschliessenden und untereinander durch eine Haut verbundenen parigen Unterkiefern und der Unterlippe.

Die derben Oberkiefer entspringen an beiden Seiten der Mundöfthung, welche Oeffinung bei den meisten Ameisen so breit als der Vorderrand des Kopfes ist (bei Anochetus ist sie viel schmäler, so dass die Oberkiefer nicht wie bei den anderen Ameisen an den Vorderecken des Kopfes entspringen, sondern aus der Mitte des Vorderrandes hervorragen). Die Oberkiefer sind stark, meistens viereckig, flach gedrückt, bogenförmig gekrümmt, mit einer convexen Aussen- und einer concaven Innenfläche, mit einem vorderen convexen und einem hinteren concaven Rande, sowie mit einem meist mit Zähnen besetzten, öfters aber nur schneidigen Kaurande. Selten sind die Oberkiefer cylindrisch, ge- 
krümmt, am Ende spitzig zulanfend (Polyergus, Fig. 22, Strongylognathus), oder etwas flachgedrïckt, gerade nach vorne gestreckt, lang und erst am Ende stark nach innen gebogen und mit 2-3 Zähnen versehen (Anochetus). Bei einer Gattung (Stigmatomma) sind die Oberkiefer schmal, am Ende spitzig und am ganzen Innenrande gezähnt.

Die Unterkiefer liegen hinter und innerhalb der Oberkiefer, durch diese von vorne und oben geschüt $\%$; sie sind dünn, plattgedrückt, bestehen aus der Angel, welche mit dem Rande der Mundöffnung articulirt, aus dem Stiele, dem grössten langgestreckten auch plattgedrïckten Theile des Unterkiefers, aus dem Lappen, der über den Stiel ragt, dreieckig und häutig ist, und endlich aus den für die Diagnostik wichtigen Kiefertastern, welche am Ende des Stieles in einer Aushöhlung desselben, nach auswärts gerichtet, eingelenkt sind. Sie bestehen aus 1-6 Gliedern, welche einfach gebaut, meist cylindrisch sind und öfters lang an der Unterseite des Kopfes herabhüngen, so dass man häufig' ohne Zerlegung des Kopfes die Anzahl der Glieder dieser Taster mit einer Loupe erkennen kann.

Die Unterlippe ist von den Unterkiefern beiderseits eingeschlossen und besteht aus dem halbmondförmigen Kinne, mittelst welchem die Unterlippe mit dem Kopfe articulirt, aus der eigentlichen Unterlippe, einer meist eiförmigen grossen Platte, an deren Vorderrande die wie die Kiefertaster gebildeten 2-4 gliederigen Lippentaster befestigt sind, zwischen welchen am Vorderende der eigentlichen Unterlippe die kleine lappige Zunge entspringt.

Die Oberlippe ist quer an der Unterseite des Clypeus nahe hinter dem Vorderrande desselben befestigt; sie ist platt, mehr oder weniger rechteckig, meist doppelt so breit als lang und deren Vorderrand ist meistens ausgebuchtet.

Der Cly peus (Kopfschild) bildet den vorderen Rand des Kopfes, liegt zwischen den Oberkiefern und Fühlern, ist von den übrigen Kopftheilen ringsum durch eine Furche meist sehr deutlich abgegrenzt; er ist dreieckig oder viereckig, erstreckt sich vorne seitlich bis zu den Oberkiefergelenken oder hilft auch dieselben dadurch bilden, dass er sich zwischen die Wangen und Oberkiefer als schmaler Streifen fortsetzt und manchmal erst an der Unterseite des Kopfes endet. Er ist hinten immer schmäler als vorne und ist entweder abgerundet oder hinten durch eine quere Linie begrenzt. Etwa in der Mitte seines Seitenrandes, welcher an die Wangen stösst, findet sich eine Grube (die ich die Schildgrube nennen will), welche nur dann deutlich ist, wenn die Fühler, vom Clypeus entfernt, entspringen (Camponotus etc.), weil sonst gewöhnlich die Schildgrube mit der Fühlergrube zusammenfällt. Der Clypeus ist meist convex, oft dachförmig, indem ihn ein Längskiel durchzieht; manchmal ist er quer eingedrückt. Sein Vorderrand ist gerade oder bogenförmig gekrümmt, besonders wenn der Clypeus die Oberkiefer theilweise bedeckt, oder es tritt der mittlere Theil desselben weiter nach vorne als der seitliche Theil, wodurch seitlich Winkel gebildet werden, oder der Clypeus ist in der Mitte ausgerandet, oder er trägt nahe der Mitte zwei Zähnchen. Ganz eigenthümlich gebildet ist der Clypeus bei Typhlopone, wo er nur als ganz schmaler Querstreifen auftritt und den Vorderrand des Kopfes bildet. 
Die Stirn le isten (laminae frontales), schmale aufgebogene Hornleisten, unter welchen die Fühler entspringen, deren freier Rand nach aussen und deren angewachsener nach innen gekehrt ist, begimnen an den Hinterecken oder an dem Ilinter- (Seiten-) Rande des Clypens, zichen sich nach hinten nnd sind einander parallel, oder divergiren nach hinten, oder krümmen sich S-förmig, oder legen sich um die Fï̈hlerwurzel herum. Sie sind gleichfïrmig schmal, oder nahe ihrem Vorderende erweitert und gehen wichtige Merkmale zur Diagnostik der Gattungen.

Die Fühler liegen unter- und ausserhall, den Stirnleisten in der Fühlergrube und bestehen aus einem meist langen, bei Männchen oft ziemlich kurzen Gliede, dem Schafte und aus einer Anzahl von kurzen Gliedern, der Geissel, welche beide zusammen ein Knie bilden. Der $\mathrm{S}$ ch a ft articulirt mit einem kugeligen Gelenkskopfe in der Fühlergrube, ist gleich nach diesem halsförmig eingeschnürt, erweitert sich aber damn gewöhnlich plötzlich, oft mit einem oder zwei Z̈̈lhnen, wird wieder dünner und ist dann stabförmig, oft flach gedrückt, und mehr oder weniger nahe dem Grunde gekrümmt, manchmal sogar winkelig gekrümmt und an dieser Stelle mit einem Lappen oder stumpfen Zahne versehen (bei Arbeitern und Weibchen ron einigen ILymica-Arten). Die Geissel besteht aus 9-12 cylindrischen, spindelförmigen oder keulenförmigen Gliedern ${ }^{1}$ ), welche entweder alle zienlich gleiche Dicke haben (fadenförmige Geissel), oder die letzteren Glieder sind durch ihre Dicke und Grösse ausgezeichnet und bilden die Ke ule, welche wieder dentlich abgegrenzt sein kann (z. B. bei Diplorlooptrum-Weibehen und Arbeitern), oder allmählich in den übrigen Theil der Geissel übergeht (wie bei Atta-Weibchen und Arbeitern).

Das Stirnfeld (area frontalis) ist, wenn es ansgeprägt ist, eine Vertiefung in dem rordersten Theile der Stirne unmittellbar hinter dem Clypeus. Es ist dreieckig, hinten öfters mit abgerundetem Eck, ist lïnger als breit oder breiter als lang, es ist gleichförmig vertieft oder in der Mitte am tiefsten, und es ist, wenn die Stirnleisten nahe an einander liegen, oft von diesen seitlich begrenzt.

Die Stirn ist jener Theil des Kopfes, welcher zwischen dem Stirnfelde (wenn diess fehlt, dem Clypeus), den Stirnleisten, den Netzungen und den Punctangen liegt: sie ist schwach gekrümmt und hat hinter den Stirnleisten keine scharfen Grenzen, welche unsichere $\mathrm{Ab}$ grenzung noch dadurch vermehrt wird, dass bei Arbeitern die Punctaugen oft fehlen und die Netzangen eine verschiedene Stellung haben. Durch die Mitte der Stirne zieht sich oft eine vertiefte Längslinie, die Stirnrinne, vom Stirnfelde bis zum Scheitel.

Der Scheitel ist durch dic drei Punctangen ausgezeichnet, welche bei Arbeitem hünfig (bei den Myrmiciden gewöhnlich) fehlen. Selten zieht sich eine tiefe Lüngsfurche bis zum IInterhauptloche.

Die Netzaugen liegen am Seitemrande des Kopfes, oder nahe demselhen an der Oberseite des Kopfes. Sie sind nahe den Hinterecken des Kopfes, oder in der Mitte des Seitenrandes, oder vorne nahe

1) Beim Mïnnchen von Pleidole pusilla Heer soll die Geissel 17 gliederig sein. Bei den exotischen Gattungen IIeptucondlylus und I'lysutte ist die Geissel nur b g gliederig. 
dem Oberkiefergelenke gelegren; sie können sogar ganz fehlen (bei Typhlopone). Sie bestehen oft aus vielen Facetten, manchmal nur aus wenigen; sie sind fast flach oder besonders bei Männchen stark halbkugelig gewölbt; sie sind selten rund, meist elliptisch oder schwach nierenförmig.

Die Ke ble ist die Unterseite des Kopfes, mit Ausnahme jenes Theiles, der von den Mundwerkzeugen in Anspruch genommen wird, und zeigt keine charakteristischen Eigenschaften. Eine Lüngslinie zieht sich von der Mitte des hinteren Mundrandes bis zum Hinterhauptloche, welches nahe dem Hinterrande des Kopfes oder an der Unterseite desselben liegt.

\section{Thorax.}

Der Thorax oder Mittelleib, vorne mit dem Kopfe, hinten mit dem Stielchen, einem abgetrennten Theile des Hinterleibes, zusammenhängend, besteht wie bei allen Insecten aus drei Theilen, deren Abgrenzung aber bei den Ameisen manchmal kaum durch eine Naht ersichtlich ist. Jeder der drei Theile besteht aus einer oberen und einer unteren Partie, so dass der Thorax im Allgemeinen in sechs Theile zerfällt.. Der vordere obere Theil ist das Pronotum (Vorderrücken), der mittlere obere das Mesonotum (Mittelrücken), der hintere obere das Metanotum (Hinterrïcken), der vordere untere das Prosternum (Vorderbrust), der mittlere untere das Mesosternum (Mittelbrust), und der hintere untere das Metasternum (Hinterbrust), von denen jeder der drei letzten Theile ein Fusspaar trägt.

Das Pronotum ist von dem Mesonotum und Prosternum meist deutlich durch Furchen getrennt; mit dem Kopfe steht es in keiner directen Verbindung und bedeckt mit einer mehr oder weniger nach vorne verlängerten, vorne abgerundeten Platte das Prosternum bis zum Kopfe. Es zeigt zwischen den Arbeitern und Soldaten einerseits und den Weibchen und Männchen anderseits eine Verschiedenheit. Bei den Ersteren ist es verhältnissmässig grösser, gewölbt und ist zur oberen Bedeckung des Thorax theilweise verwendet; von oben gesehen zeigt es sich mehr oder weniger halbmondförmig, indem sich die Seiten ziemlich weit nach rückwärts ziehen. Bei den Weibchen und Männchen hat das Pronotum gewöhnlich nur die Form einer auf die Kante gestellten nach rückwärts gebogenen Schiens, Fig. 29a, deren untere Kante mit dem Prosternum in Verbindung steht und auf deren oberen das Mesonotum aufliegt und von diesem öfters überragt wird. Nur selten wird das Pronotum bei den geflügelten Ameisen auch zur theilweisen Bedeckung der oberen Fläche des Thorax verwendet.

Das Mesonotum der Arbeiter und Soldaten besteht (sowie das Pronotum) nur aus einem einzigen Stïcke, welches bei den meisten Gattungen nur in der Form einer gewölbten Scheibe an der oberen Seite des Thorax auftritt und sich ziemlich selten an den Seiten desselben verlängert (wie z. B. bei Camponotus). Bei den Weibchen und Männchen besteht es ans dem grössten Stücke, nämlich dem eigentlichen Mesonotum, ferner aus den Seitenlappen, aus dem Schildchen und dem Hinterschildchen. Das eigentliche Mesonotum, Fig. 29b, nimmt die vordere Hälfte des Riickens ein, ist in der Mitte 
mehr oder weniger flach, vorne und seitlich herabgebogen und mit dem Pronotum und Mesosternum in Verbindung; bei vielen Männchen der Myrmiciden begimnen vorne seitlich am eigentlichen Mesonotum zwei vertiefte Furchen, welche nach hinten und einwärts ziehend sich in der Mitte desselhen vereinigen, von wo eine Furche gerade nach hinten zieht. Die Seitenlappen, Fig. 29 und $30 c$, sind dreieckige Stïcke zwischen dem eigentlichen Mesonotum, dem Schildchen und der Vorderflügelwurzel. Das Schildchen (Scutellum), Fig. 29 und 30d, ein dreieckiges Stïck, ist besonders hinten stark gewölbt und länft in einen stumpfen Zapfen aus; es ist seitlich eingedruickt zur Aufnahme der in Ruhe gelegten Vorderflügel. Das Hinterschildchen (Postscutellum), Fig. 29 und $30 e$, ist ein querer, von vorne nach hinten gewölbter Gürtel, der sich seitlich in zwei Arme theilt, zwischen welchen die Hinterflügel entspringen.

Das Metanotum, Fig. 29 und $30 f$, besteht aus einem Stricke; es ist meist schief anf das Metasternum aufgesetzt und zeigt eine verschiedene Form. Bei den einen ist es stark gewölbt, kegel- oder buckelförmig (wie z. B. beim Arbeiter von Formica, Polyergus), bei anderen ist es gewölbt, seitlich zusammengedrüickt und viel länger als breit (z. B. bei den Arbeitern von Camponotus), oder es ist eckig, wie ein schief abgeschnittenes Segment eines Würfels mit einer oberen Basal-, einer hinteren abschüssigen Fläche und mit Seitenflächen, welche Flächen oft ohne Grenze in einander übergehen. An der Grenze zwischen der Basal- und der abschüssigen Fläche entspringt häufig an den beiden seitlichen Ecken ein Zahn oder Dorn mit gerader Richtung nach hinten, oder nach hinten und oben. Bei Männchen und Weibchen ist seitlich zwischen dem Metanotum, dem Hinterschildchen, dem Mesosternum und Metasternum unter dem Ansatze der Iinterflügel ein gewöhnlich dreieckiges Seitenstïck eingekeilt.

Das Prosternum, Fig. $29 \mathrm{~g}$, dessen vorderer Theil mit dem Kopfe in Gelenksverbindung steht, liegt an der Unterseite des Thorax, besteht aus zwei unteren, in der Mitte mit einer Längsnaht verbundenen Platten, welche hinten zur Aufnahme der Vorderbeine ausgeschnitten sind, ferner aus seitlichen mach aussen und oben gestellten, von den Platten durch eine scharfe Kante getrennten Leisten, welche mit dem Pronotum in Verbindung stehen.

Das Mesosternum besteht bei den Arbeitern und Soldaten aus einer unteren flachen Platte, welche hinten die Mittelbeine trägt, und aus den von diesen durch eine scharfe Kante getrennten seitlichen Schulterstïcken (Scapulae), Fig. 29h. Bei Weibchen und Männchen ist die Platte gross und biegt sich an die Seiten des Thorax herauf, Fig. $29 i$.

Das Metasternum, Fig. 29k, ist gewöhnlich sehr klein und besteht aus einer kleinen Platte, welche die Hinterbeine trägt.

\section{Hin terleib.}

Der Hinterleil) besteht aus sechs, bei den Männchen aber aus sieben Segmenten, von denen jedes aus einem oberen und einem unteren Stücke besteht. Der Hinterleib der Ameisen besteht aus dem Stielchen, 
d. i. dem vorderen kleinen, stark abgesehnïrten Theile und aus dem eigentlichen Hinterleibe.

Das Stielehen (Petiolus) besteht aus einem oder aus zwei Segmenten ${ }^{1}$ ). Ist das Stielchen eingliederig, so hat es entweder die Form eines kurzen dicken Stieles, welcher oben einen kugeligen Knoten oder, was meistens vorkömmt, eine von vorne nach rückwärts zusammengedrückte Platte, S c h u pp e (Squama petiolaris) genannt, trägt, oder es kann das ganze Stielchen von oben nach unten flachgedriickt sein (Tapinomn, Fig. 17 und 18), oder dasselbe kann kubisch mit abgerundeten Ecken sein (Typhlopone). Die Schuppe zeigt verschiedene Abänderungen; sie kamn gross oder klein, kreisrund oder schmal mit parallelen Seiten, ganzrandig oder oben ausgerandet, eingeschnitten und zweizähnig sein; sie kann aufrecht oder nach vorne und oben geneigt sein; sie kann keilförmig, unten dick nach oben dünn zulaufend sein. Ist das Stielchen zweigliederig, so ist das erste Glied vorne gewöhnlich cylindrisch (stielförmig), hinten oben knotenförmig oder mit einem Querwulste versehen, selten vorne und hinten fast gleichbreit oder trapezförmig und von oben nach unten zusammengedrückt. Dieses erste Glied hat unten vorne fast immer einen kleinen Fortsatz als Hemmungsmittel für die zu starke Abwärtskrümmung des Stielchens, da sich dieser Fortsatz an das Metasternum stemmt. Das zweite Stielchenglied ist knotenförmig, ohne Stiel, so breit als lang oder breiter.

Der eigentliche Hinterleib articulirt an seinem vordersten Ende mit dem Stielchen, nur bei einer Gattung (Cremastogaster) befestigt er sich mit seiner Oberseite nahe dem Vorderende an das Stielchen. Er ist kugelig, eiförmig, länglich oder herzförmig, meist ohne Einschnürung und ist nur bei den Poneriden zwischen seinem ersten und zweiten Segmente eingeschnïrt. Er besteht aus fünf Segmenten bei jenen Ameisen, welche ein eingliederiges Stielchen haben, und aus vier Segmenten bei jenen mit zweigliederigen Stielchen; die Männchen haben stets um ein Segment mehr. Jedes Segment besteht aus einer kurzen breiten Rückensehiene, welche sich seitlich bis zur Unterseite des Hinterleibes verlängert und aus einer Banchschiene, deren Enden von der Rückenschiene bedeckt werden. Die HinterleibsSegmente sind in ihrer Länge sehr verschieden; meist sind die ersteren Segmente viel grösser als die letzteren, oft bedeckt (bei den M/yrmicirlen besonders) das erste Glied fast alle folgenden, manchmal sind alle Segmente ziemlich gleichlang (bei Cataglyplis Männchen). Jedes Hinterleibs-Segment ist (bei gedachtem senkrechten Schnitte von rechts nach links) fast kreisrund (Cataglyphis) oder sehr stumpf dreieckig bei oben flachem Hinterleibe, oder oval, wo er oben und unten gleichformig gewölbt und breiter als hoch ist. Die Bauchschiene des letzten Hinterleibs-Segmentes bei den Männchen, Ventralplatte, Fig. 20, genannt, zeigt besondere Verschiedenheiten. In den meisten Fällen ist sie eine fast halbkreisförmige Platte mit der Krümmung nach hinten, doch bei Cataglyplis viaticus setzt sie sich hinten in drei Dornen fort und bei Tupinoma ist sie in der Mitte bis zum Grunde ausgeschnitten

1) Losana will sogar eine Aneise mit cinem dreiglicilerigen Stielchen (Mymica trinodis) gefunden haben. 
und dadurch in zwei Lappen getheilt, welche sich in einen Fortsatz verlängern.

Die äusseren Genitalien der Männchen liegen am oder an der Unterseite des Hinterleibes ziemlich nahe dem hinteren Ende des IInterleibes; sie sind bei manchen Gattungen sehr gross, bei anderen aber sehr klein, kaum dass einzelne Theile derselben hervorragen. Dieselben bestehen aus folgenden Theilen: 1. die Penicilli; 2. die Schuppen; 3. die äusseren; 4. die mittleren und 5. die inneren Genitalklappen. Die Penicilli, zwei tasterartige, eingliederige Stiele, entspringen unterhalb der Rückenschicne des letzten Hinterleibs-Segmentes von einer kleinen viereckigen Platte und ragen gerade nach rückwärts. Bei einer Gattung (C'ataglyplis) fehlen dieselben. Die S ch uppen liegen beiderseits, die Genitalien seitlich schützend; sie sind aussen convex, inmen concav, mehr oder weniger halbkreisförmig. Die äus seren Genitalklappen, Fig. 11, welche bei der Diagnostik wegen ihrer leichten Zugänglichkeit von besonderer Wichtigkeit sind, treten unter den Schuppen hervor, sind messerförmig, dreieckig, dornförmig u. s. w., haben entweder keinen seitlichen Fortsatz, oder (bei Cataglyphis) innen ein fast löffelartig geformtes horniges Anhängsel. Die mittleren Genitalklappen (Zwischenklappen), Fig. 12, sind so wie die vorigen hornig; sie bestehen aus einer Platte, welche verschiedene Formen bei den verschiedenen Gattungen hat. Die inneren Genitalklappen, Fig. 13, sind fast häutig und ihre Platten bilden eine Scheide zum Durchtritte des Penis.

\section{Flüg el.}

Die geschlechtlichen Ameisen haben vier häutige Flügel, welche den Geschlechtslosen fehlen. (Oft findet man Weibchen, welche ihre Flïgel bereits verloren haben, welche aber als solche leicht an der Bildung des Thorax zu erkennen sind. Die Flügel der Männchen sind ganz gleich jenen der Weibchen und daher bei der Charakteristik der Gattungen nur bei den Weibchen besprochen.

Die Vorderflügel (in folgenden Tabellen schlechtweg Flügel genannt) articuliren mit dem Thorax zwischen dem Mesonotum, den Seitenlappen und der Scapula. Vom Grunde der Vorderflügel entspringen vier Längsrippen. Die erste, die Randrippe (Costa marginalis), Fig. 1 a, begrenzt den Aussemrand des Flügels und reicht etwa bis zur Flügelspitze. Die zweite, die Schulterrippe (Costa scapularis), Fig. $1 b$, liegt fast parallel der Randrippe, ist vor dem Ende des zweiten Drittheils des Flügels ihr genähert, bildet mit ihr das hornige dunkel gefärbte Randmal, Fig. $1 c$, und verbindet sich dann vollkommen mit der Randrippe; nur bei Myrmecina entfernt sich letztere hinter dem Randmale vom Flügelrande und verbindet sich mit der Schulterrippe. Die dritte, die Mittelrippe (Costı media), Fig. 1d, theilt sich vor der Mitte des Flügels in zwei divergirende Aeste; der äussere Ast, die Grundrippe (Costa basalis), Fig. le, ist meist winkelig gebogen und verbindet sich mit der Schulterrippe, der innere Ast (ohme diagnostischen Werth), Fig. 1f, zicht in schiefer Richtung gegen den Innenrand des Flügels und schickt noch vor seinem Ende oft einen gegen das Ende des Flügels ziehenden $\Lambda$ st ab. Beiläufig von der 
Mitte der Grundrippe entspringt die wichtige ('ubitalrippe, Fig. $1 g$, welche gegen die Flügelspitze zieht, sich meist in zwei Aeste, Fig. $1 i k$, theilt, die in derselben Hauptrichtung verlaufen. Von der Schulterrippe, an der Stelle, wo sie das Randmal begrenzt, kommt die kurze Q uerrippe, Fig. 1l, welche sich mit dem Stamme oder mit den Aesten der Cubitalrippe verbindet. Die näheren Verhältnisse des Verlaufes dieser Rippe und die Verbindung mit der Querrippe sind folgende: 1. Die Querrippe verbindet sich mit der Cubitalrippe an oder nahe der Stelle, wo sie sich in ihre zwei Aeste theilt, Fig. 1; 2. die Querrippe verbindet sich bloss mit dem äusseren Cubitalaste, Fig. 3; 3. die Querrippe verbindet sich mit beiden Cubitalïsten, Fig. 4; 4. der Anfang des äusseren Cubitalastes ist nicht ausgebildet und die Querrippe verbindet sich mit beiden Cubitalästen, Fig. 5. Die Mittelrippe verbindet sich oft durch eine quere Rippe, die zurü ck la u f en de Rippe (Costa recurrens), Fig. $1 l$, genannt, mit der Cubitalrippe. Die vierte Rippe, die Innenrippe (Ć.interno-media genannt, wenn man die Mittelrippe als externomedia bezeichnet), Fig. I $m$, ist unwichtig; sie zieht fast parallel mit dem Innenrande des Flügels und schickt einen Querast zur Mittelrippe. - Von diesen Rippen werden nur wenige Zellen vollkommen abgegrenzt. An der Flügelbasis liegen die Schulterzelle, Fig. I $\alpha$, zwischen der Rand- und Schulterrippe, die äussere Mittelzelle, Fig. $1 \beta$, zwischen der Schulter -, Mittel- und Grundrippe, und die innere Mittelzelle, Fig. $1 \gamma$, zwischen der Mittel- und Innenrippe und dem Queraste. Zwischen der Grund-, Cubital- und Schulterrippe liegen ein oder zwei Cubitalzellen; bei der Beschreibung der Cubitalrippe wurden vorstehend viererlei Rippenvertheilungen angeführt; im ersten Falle wird eine Cubitalzelle von der Grund-, Schulter-, Querrippe und dem Stamme der Cubitalrippe begrenzt, Fig. $1 \delta$; im zweiten Falle ist auch nur eine Cubitalzelle vorhanden, zu deren Begrenzung noch der äussere Cubitalast beiträgt, Fig. $3 \delta$; im dritten Falle werden zwei Cubitalzellen gebildet, und zwar die vordere äussere Zelle durch die Grund-, Schulter-, Quer-, Cubitalrippe und den äusseren Cubitalast, Fig. $4 \delta$, die hintere innere Cubitalzelle wird von den beiden Cubitalästen und der Querrippe begrenzt, Fig. $4 \varepsilon$; im vierten Falle wird e in e halbgetheilte Cubitalzelle durch die Grund-, Schulter-, Querrippe und Cubitalrippe gebildet, Fig. $5 \delta$. Die Discoidalzelle, Fig. $1 \xi$, ist dann abgegrenzt, wenn die zurücklaufende Rippe vorhanden ist; sie wird durch diese, die Cubital-, Grundrippe und den inneren Ast der Mittelrippe gebildet.

Die kleinen Hint erflügel, Fig. 2, welche keinen diagnostischen Werth haben, sind von drei Längsrippen durchzogen. Die erste äussere, die Schulterrippe, tritt in der Hinterhälfte des Flügels an den Aussenrand. Die Mittelrippe theilt sich vor der Mitte des Flïgels in zwei Aeste, von denen der äussere sich mit der Schulterrippe mittelst eines Querastes oder durch directe Berührung verbindet und gegen das Ende des Flügels zieht. Die dritte Rippe, die Innenrippe verbindet sich entweder mittelst eines Querastes mit der Mittelrippe und zieht in der gleichen Richtung weiter, oder sie biegt sich gegen die Mittelrippe und endet in derselben. 
B e in e.

Jedes Bein besteht aus der Hüfte, dem Schenkelringe, dem Schenkel, der Schiene und der Tarse (Fuss).

Die Hüfte ist eiförmig oder lïnglich-eifürmig, an den Vorderbeinen gewöhnlich viel länger und grösser als an den Mittel- und Hinterbeinen (bei Typlilopone sind alle ziemlich gleich gross).

Der Schenkelring besteht bei allen Ameisen nur aus einem Stïcke (ebenso wie bei den übrigen Raubwespen und Bienen, während er bei den Blatt-, Holz-, Schlupf- und Gallwespen aus zwei Stücken besteht).

Die Schenkel sind gleichbreit, meist flachgedrückt, spindel-oder keulenförmig.

Die Schienen sind am Grunde dünn, werden gegen das Ende dicker und tragen etwas vor demselben am inneren Rande an den Vorderbeinen einen kammförmig gezähnten Sporn, an den Mittel- und IIinterbeinen entweder einen einfachen dornförmigen, oder ringsum mit feinen Spitzen versehenen, oder kammförmig mit Dörnchen versehenen s porn (in den Tabellen sind unter dem Ausdrucke Sporne nur jene der Mittel- und Hinterbeine verstanden).

Die Tars en sind stets fünfoliedrig; das erste Glied ist das längste, es ist oft länger als die. Schiene, es ist an den Vorderbeinen nahe dem Grunde gebogen (um beim Putzen den Fühler oder ein anderes Bein zwischen dieser an der Innenseite dicht mit Haaren wie bei einer Bürste versehenen Biegung des ersten Tarsengliedes und dem kammförmigen Sporne durchzuziehen und zu reinigen); bei den Mittel- und Hinterbeinen findet sich am ersten Tarsengliede keine solche Krümmung. Das zweite Tarsenglied ist viel kürzer als das erste, das dritte ist noch kürzer, das vierte ist das kürzeste und das fünfte ist wieder etwas länger als das vierte und trägt die zwei gekrümmten Krallen, welche bei europäischen Ameisen nie kammartig gezähnt sind, sondern nur bei wenigen Männchen am Grunde ziemlich undeutlich mit einem kurzen Zahne versehen sind. Zwischen den Krallen sitzt ein horniger 4-5eckiger Lappen, Haftlappen genannt, der gewöhnlich kürzer als die halbe Kralle ist und nur bei wenigen Ameisen diese Grösse überschreitet.

\section{Weibchen, Männchen, Arbeiter und Soldaten.}

Die geschlechtslosen Ameisen, die Arbeiter und Soldaten, unterscheiden sich ron den geschlechtlichen dadurch, dass sie niemals geflïgelt sind und dass ihr Thorax viel einfacher gebildet ist, und zwar besteht das Mesonotum nur aus einem Stücke, während bei den Weibchen und Männchen dasselbe in das eigentliche Mesonotum, das S'childchen, Hinterschildchen und in die Seitenlappen zerfällt. Zur Unterscheidung der Arbeiter von den Soldaten kann kein allgemeiner Charakter angegeben werden. Unter den europäischen Ameisen kommen nur bei einer Gattung (Pheidole) Soldaten vor, welche sich durch ihren grossen Kopf und ihre schneidigen Oberkiefer leicht von den Arbeitern unterscheiden, während bei der Gattung Atta die grossköpfigen Geschlechts. losen durchaus nicht als Soldaten anzusehen sind, da man, wemn eine grössere Anzahl Individuen in einem Baue angetroften wird, leicht die 
Uebergänge von denjenigen Individuen, welehe ganz kleine Köpfe haben, bis zu jenen verfolgen kann, welche riesige Köpfe besitzen, wohei auch die Körpergrösse eine bedeutendere ist, während diess bei Pheidole niemals stattfindet.

Die Weibchen sind geflügelt, doch verlieren jene, welche nach dem Fluge in das Nest zurückkehren, von selbst die Flügel, oder sie werden ihnen von den Arbeitern abgebissen, doch sind solche Weibchen leicht durch die oben angeführten Charaktere, sowie durch die stets zurïckbleibenden Flügelgelenke von den Geschlechtslosen zu unterscheiden.

Die Männchen sind von den vorigen am leichtesten dadurch zu unterscheiden, dass sie um ein Hinterleibs-Segment mehr haben. Ueberdiess unterscheiden sie sich von den Weibchen, mit welchen sie verwechselt werden könnten, durch den kleineren Kopf, durch dünnere und längere Beine, durch schmälere Oberkiefer, durch die äusseren Genitalien, sowie auch dadurch, dass sie um ein Fühlerglied mehr besitzen; ihre Flügel verlieren sie niemals.

Die Bezeichnung der Arbeiter ist §̧, die der Weibchen \&, und die der Männchen $\widetilde{\sigma}^{\text {. }}$

Die geflügelten Ameisen finden sich in den Colonien nur kurze Zeit, doch hauptsächlich in den ersteren Sommermonaten, obschon man sie schon im Februar und im Spätherbst manchmal findet. Ich unterlasse es, die Schwärmzeit der einzelnen Arten anzugeben, da diese in den verschiedenen Breiten Europa's eine sehr verschiedene ist.

\section{Aufenthalt.}

Die Ameisen legen ihre Colonien vorzüglich in der Erde an, in welcher sie Gänge und Kammern ausgraben und das dabei gewonnene Materiale entweder an der Oberfläche des Bodens vertheilen oder dasselbe nebst anderem Materiale (Blätterstückchen, Coniferen-Nadeln, Grashalmstückchen u. s. w.) zum Aufban eines Hügels über den inneren Erdbau benützen, welcher Hügel dann ebenfalls mit Gängen durchzogen ist, und bei Tage viele Oeffnungen zum Aus- und Eintritt der Ameisen besitzt, öfters aber mündet der unterirdische Bau an der Oberflïche mit einer einzigen Oeffnung, welche ringsum kraterartig mit Erde umgeben wird. Die Ameisen - Colonien finden sich auch unter Baumrinden, in welche sie sich Gänge nagen, oder in hohlen Bäumen, in Mauerritzen, zwischen Moos, ja sogar die Häuser sind öfters von ihnen bewohnt, wo manchmal nicht nur europäische Arten (z. B. Tetramorium caespitum), sondern anch exotische Arten vorkommen; ganz vorzüglich aber finden sich letztere in Glashäusern, in welche durch exotische Pflanzen Ameisen eingeschleppt werden, die sich sodann acclimatisiren.

In Betreff der einzelnen Gattungen und Arten ist Folgendes bemerkenswerth:

Camponotus. Die Arten dieser Gattung legen ilre Bauten in hohlen Bäumen und in der Erde unter Steinen, besonders an sonnigen Bergabbängen an, nur C. Terculeanus und ligniperdus lieben bewaldete Gebirgsgegenden, besonders erstere Art. C. fallax, marginatus und lateralis leben auch in Mauerspalten und 
sind oft auf Bäumen anzutreffen, auf welchen sie die Blattläuse aufsuchen, um den von letzteren ausgeschiedenen Zuckersaft zu lecken.

Colobopsis truncuta lebt in minirten Gängen von Aesten der Bïume und Striucher, sowie in leeren Galläpfeln. C. fuscipes aber liebt hohle Bäume, in welchen sie nistet.

Liometopum. Die einzige zu dieser Gattung gehörige Art lebt auf Büumen, auf denen man sie processionsartig ziehen sieht.

Hypoclinea. Dic durch die vier leichten Puncte am Hinterleibe leicht erkennbare Art legt ihre Colonien in Bäumen und im abgestorbenen Holze an.

Tapinoma erraticum. In Erdbauten unter Steinen inf sonnigen trockenen Hügeln, erwacht an warmen Wintertagen aus dem Winterschlafe und ist sodann unter Steinen zu finden.

Acantholepis lebt unter Steinen oft in grossen Colonien.

Plagiolepis nistet an warmen dürren Hügelabhängen unter Steinen und findet sich häufig in den Blüthen verschiedener Pflanzen, besonders aber in Compositenköpfehen.

Polyergus lebt in Erdhauten, welche mit der Oberfliche mittelst einer einzigen Oefinung in Verbindung stehen.

Cataglyphis. Beich. Arten erzeugen Eribanten besonders in der Ebene oder auch in Gebirgen, welche Ebenen begrenzen.

Formica. Alle Arten leben in Erdbauten, theils mit dieselben bedeckenden Hügeln, theils unter Steinen. $F$. rufa lebt besonders in Gebirgen in dichten Nadelholz- (seltener Laubholz-) Wäldern, wo sie riesige, $3-4$ Fuss über der Oberfläche des Borlens erhabene Ilügel aus Coniferen-Nadehn, Erdklümpehen, Blattstücken, 'Zweigstückeben u. s. w. errichtet. $F$, congerens lebt in Gebirgen, besonders auf Waldwiesen, in fast flachen, viel kleincren Bauten, welche aus demselben Materiale bestehen, wie bei der vorigen Art. Die Arten $F$. sanguinea, truncicola, exsecla und pressilabris finden sich in Gebirgen an warmen sonnigen Stellen in Baumstrünken, in alten hohlen Bäumen oder in der Ède mit klcinen Erdhügeln, aus Erde, Grasstückchen, Coniferen-Nadeln u. s. w. bestehend, oder auch unter Steinen. $F$. cinerea lebt vorzüglich an Fluss- und Bachufern im Gerölle und auf den in der Nähe vorhandenen feuchten Wiesen in Frdbauten. F. fusca und cunicularia finden sich überall in der Ebene und im Gebirge, häufig in Erdbauten mit kleinen Hügeln und unter Steinen. F. gagates liebt Laubholzwaldungen, besonders Eichenwälder, in welehen sie meist versteckte Eribauten errichtet und vorzüglich anf Eicken oft in Masse zu finden ist, auf welchen sie den Blattliusen des Zuckers wegen nachgeht. Der Aufenthalt von $F$. subrufa ist mir unbekannt.

Lasius fuliginosus lebt in alten Bäumen in von ihm ausgenagten Crängen, auch bildet sie manchmal in ten IHöhlungen der Bäume aus Erde zusammengekittete Baue mit weiten Kammern und Gängen; sie findet sich im Gebirge und in der Ebenc. L. niger und alienus finden sich niberall in Erdbanten, in hoblen Bäumen, zwischen Moos u. s. w. L. cmarginatus lebt besonders in Gärten, in Mauerritzen. L. brunneus, weleher sich durch seine Furchtsamkeit auszeichnet, lebt auf Bäumen. Die gelben Arten dieser Gattung leben in Erdbauten mit aus Erde bestehenden Hügeln oder unter Steinen.

Prenolepis. Dic Banten sind mir noch unbekannt; ich fand sic auf Eichen, auf denen sie Blattliuse aufsuchen; auch in Weingärten wurden siu, Traubensaft leckend, gefunden.

Anochetus. Typhlopone. Deren Aulentbalt ist mir noch unbekannt. 
Stigmatumma denticulatum wurde unter einem alten Balken am Monte Scapo auf der Insel Zante aufgefunden.

Ponera lebt in sehr kleinen Colonien in der Erde unter Stcinen oder zwischen Moos, besonders auf sonnigen Bergabhängen.

Stenamma findet sich nur in den Colonien der Formica rufa und congerens.

Tomognathus lebt in den Colonien von Leptothorax acervorum und muscorum.

Strongylognathus findet sich selten unter Steinen mit $\Varangle$ von Tetramorium caespitum und scheint diese zu rauben (sowie Polyergus die Formica cunicularia raubt), da sie wegen ihres mit Polyergus gleichen Kieferbaues nicht zu bauen im Stande ist.

Tetramorium caespitum findet sich fast überall, wo organisches Leben ist; auf Wiesen bildet sie Erdhügel.

Leptothorax. Die Arten dieser Gattung leben unter der Rinde der Laubbäume, auf welchen sie laufend gesehen werden, oder auch in Felsspalten zwischen Moos, sowic in leeren Galläpfeln; fast nur $L$. unifasciatus lebt unter Steinen auf sonnigen warmen Hügeln. Letztere Art findet sich häufig, während alle anderen Arten durchschnittlich selten sind und in kleinen Colonien leben.

Myrmica. Die hicher gehörigen Arten bauen keine Hügel, sondern miniren blos in der Erde und finden sich unter Steinen, selten zwischen Moos und in alten Baumstrünken.

Atta. Hauptsächlich unter Steinen; A. structor erzeugt Bauten in der Erde, welche mittelst einer Oeffnung, die mit loser Erde kraterförmig umgeben ist, mit der Oberfläche in Verbindung stehen.

Temnothorax. Aufenthalt mir unbekannt.

Pheidole. Die zwei Arten leben unter Steinen in der Erde, aber auch in Häusern, in welchen sie grossen Schaden verursachen und sich besonders als Feinde der Insecten-Sammlungen auszeichnen.

Monomorium. Der Aufenthalt der Colonien der beiden Arten ist mir unbekannt : M. minutum fand ich auf Grashalmen.

Diplorhoptrum fugax lebt unter Steinen in der Erde in stark bevölkerten Colonien, besonders an warmen Bergabhängen.

Myrmecina findet sich in der Erde unter Steinen in sehr kleinen Colonien.

Cremastogaster nistet in Mauerspalten oder unter Steinen, ziehen vom Bauc aus processionsweise auf die Bäume, um Blattläuse aufzusuchen.

\section{Geographische Verbreitung.}

Die bekannte Thatsache, dass die Verbreitungsgrenze der Thiere und Pflanzen mehr oder weniger von den Isotheren-Curven (Iinien gleicher, mittlerer Sommer-Temperatur) abhängt, bestätigt sich auch bei den europäischen Ameisen. Es waltet nur der unangenehme Umstand $\mathrm{ob}$, dass die Meteorologie in Bezug der Bestimmung der Isotherenlinien noch nicht weit vorgeschritten ist und die Zeit ziemlich ferne zu sein scheint, bis diese Linien sicher markirt sein werden. Ein Theil der Ameisenarten ist in ganz Europa verbreitet, deren Begrenzung gegen Osten und Süden noch ziemlich unsicher ist, doch lässt sich bereits angeben, dass viele dieser Arten über den Ural durch die sibirische Ebene bis nach Nordamerika verbreitet sind, sowie sie auch südlich nach Afrika übergreifen. Ein anderer Theil der Arten findet sich nicht im nördlichen Europa und die nördliche Verbreitungsgrenze ist bei diesen 
Arten eine sehr rershiedene. So finden sich Artan, welche nit dor Isothere des 18. und 19. Wärmegrades (Celsius) ilne nordiche Be. grenzung finden, wie Mypoclinea quadripunctata, 'lagro'epis muima"a, Polyergus rufescens, Formica cinerea, Lasius emarginitus aizenus. affinis, Strongylognathus testaceus, Leptothorax Gredleri, Myymica mbida, Atta structor, subterranea. Eine andere Reihe reicht nicht so weit nach Norden, sie übergreift nicht das dentsche Mittelgehirge und die Karpathen, und ist beiläufig durch die Isothere des 20. Wärmegrades begrenzt. Hieher gehören : Camponotus marrinatus, aethiops, lateralis, Colobopsis truncata, fuseipes, Liometopum mierocephalum, I'renolepis mitens. Eine fernere Reihe hat ihre nördliche Verbreitungsgrenze so ziemlich mit der der immergrünen Laubhölzer gemein, wird durch die Isothere des 21. Wärmegrades begrenzt und gehört zur eigentlichen MediterranFanna; so: Atta barbara, Iheidole meqarephala. ILonomorium mimutum, Cremastogaster scutellaris und sordidula. Schliesslich finden, sich auf den sïdeuropäischen Halbinseln und Inseln noch manche Arten, welche höchst wahrscheinlich ihre Iauptverbreitung im nördlichen Afrika hahen, wie z. B. Camponotus micans, Atta striola, testaceo-pilosa, 1/onomorium merliterreneum.

Ich rermeide es indessen, mich hier näher in die Besprechung. über die Verbreitung der Ameisen im Allgemeinen einzulassen und behalte mir diess für eine spätere Zeit auf, wo vielleicht schon gewisse Lïcken ausgefüllt sein werden.

Ueber die Arten im besonderen ist Folgendes bemerkenswerth:

Camponotus ligniperdus und herculeanus finden sich von Europa bis Ostsibirien und Nordamerika, von der Ebene bis in die höchsten Alpen.

Camponotus pubescens ist in Europa nördlich durch die Isothere des 20.5 . Wärmegrades begrenzt, reicht östlich nach Asien bis Amasia, findet sich in Afrika auf Madeira, und lebt auch im östlichen Nordamerika zwischen dem 30. und 41. Grade nördlicher Breite von New-Orleans bis New-York. Nach Nylander soll diese Art auch auf der Insel Gottland vorkommen.

Camponotus fallax in ganz Südeuropa bis zur Isothere des $19.5 \mathrm{Wgrr}$. In Nordamerika bis New-York.

Camponotus marginatus in Südeuropa bis zur Isothere des 20. Wgr. In Afrika an der Nordküste von Marokko bis Egypten.

Camponotus aethiops reicht nördlich bis zur Isothere des $20^{\circ} 5 \mathrm{Wgr}$., östlich bis in die Krimm und nach Brussa in Kleinasien. Smith's Angabe im Cat., dass diese $A \mathrm{rt}$ bei Helsingfors vorkomme, ist entschieden ein Schreibfebler, ebenso ist mir die Angabe: "Provinz Preussen" in v. Siebold's Beitr, z. Faun. d, wirbell. Thiere d. Prov. Preussen unwahrscheinlich.

Camponotus micans im südlichsten Europa bis zur Isothere des 24. Wgr. (Sicilien, Andalusien); in Afrika in Algier.

Camponotus cruentatus wurde im südwestlichen Europa am Südrande von Frankreich und auf der pyrenäischen Halbinsel, sowie in Afrika am Nordrande gefunden.

Camponotus lateralis in Sudeuropa bis zur Isothere des 20. Wgr., auch in Nordamerika.

Camponotus Kiesenwetteri bis jetzt blos auf der Insel Zante und am gricchischen Festlande gefunden.

Colobopsis truncata und fuscipes in Südeuropa bis zur Isothere des $20^{\circ} 5$. Wgr. Liometopum microcephalum in Südeuropa bis zur Isothere des $20^{\circ} 5$. Wgr., doch nur ostwärts vom. 27. Grade östlicher Länge. 
Hyroclirag quadripirictata bis zur Isothere des 18. Wgr.

'Tapiroma erraticum findei sich beilaufig bis zur Isothere des 15 . Wgr., also iln "grôsster' 'Theile' Europa's.

Tapinuraa rairuim ist nur von Pisa bekannt.

Acantholepis Frauenfeldi findet sich auf der Balkan-Halbinsel (Sign in Dalmatien, Insel Zante und Konstantinopel).

Plagiolepis pygmaea auf der südlichen Hälfte von Europa bis zur Isothere des 19. Wgr. In Afrika auf Madeira.

Polyergus rufescens bis zur Isothere des 18. Wgr.

Cataglyphis viatica findet sich in den Lïndern, welche das Mittelmeer und seine Buchten umgeben, obwohl sie sich auch ziemlich weit davon entfernt. In Südeuropa lebt sie auf der pyrenäischen und Balkan-Halbinsel (verbreitet sich aber von dieser nördlich bis Pest-Ofen), ferner zwischen dem caspischen See und dem schwarzen Meere. In Asien wurde sie von Kleinasien bis Bokhara gefunden, in Afrika vom Nordrande bis Nubien.

Cataglyphis cursor hat in Europa so ziemlich dieselbe Verbreitung wie die vorige Art, doch reicht sie im westlichen Europa bis nach Südfrankreich. In Asien findet sie sich in der Kirgisen-Steppe.

Formica pressilabris. Deren Verbreitung ist wegen ihres seltenen Vorkommens wohl noch nicht binreichend bekannt; sie wurde bis jetzt nur im östlichen Theile von Europa gefunden, dürfte aber in ganz Europa, sowic $F$. cxsecta, verbreitet sein.

Formica exsecta in Europa, ausser Britannien und den südlichen Halbinseln und Inseln; sie findet sich von Lappland bis in die Lombardie.

Formica subrufa nur aus Andalusien und Georgien bekannt.

Formica sanguinea in Europa, mit Ausnahme der südlichen Halbinseln und Inseln, bis Ostsibirien und Nordamerika.

Formica truncicola in Europa von Lappland bis Piemont.

Formica rufa und congerens in Europa bis nach Ostsibirien, erstere Art auch in Nordamerika.

Formica cinerea im südlichen Europa bis zur Isothere des 18. Wgr.

Formica cunicularia überall in Europa bis in die Mongolei und nach Ostsibirien.

Formica fusca in ganz Europa, ferner auf Madeira in Afrika und in Nordamerika.

Formica gagates in Europa, von Finnland bis zu den Suidspitzen Europa's; in Asien bis in die. Alpen der Mongolei und nach Ostsibirien.

Lasius fuliginosus in Europa. Noch nicht auf der pyrenäischen und BalkanHalbinsel aufgefunden.

Lasius niger in ganz Europa, auf Madeira und in Nordamerika.

Lasius alienus auf der Südbälfte Europas bis zur Isothere des 18 . Wgr.

Lasius emarginatus von den Mittelmeer-Ländern bis zur Isothere des 19 . Wgr.

Lasius brunneus bis zur Isothere des 16 . Wgr.

Lasius mixtus in Europa, noch nicht auf den britischen Inseln und südlichen Gliedern Europas gefunden.

Lasius incisus bisher nur in Nassau.

Lasius umbratus in Europa und in Nordamerika, bisher nicht auf der pyrenäischen und Balkan-Halbinsel aufgefunden.

Lasius fiavus in Europa, doch nicht auf der pyrenäischen und Balkan-Halbinsel bis jetzt entdeckt.

Lasius affinis in Deutschland (von Nassau und Preussisch-Schlesien südlich) und im Kirchenstaate. 
Lasius carniolicus in Krain.

Lasius bicornis in Nassau.

? Lasius crepusculascens in der nördlichen Türkei.

Prenolepis nitens von Tirol bis Siebenbürgen und ron Unterösterreich bis Krain.

Typhlopone europaea bei Turin.

Stigmatomma denticulatum auf der Insel Zante.

Anochetus Ghilianii in Andalusien.

Ponera contracta in ganz Europa; in Afrika, auf Madeira, in Nordamerika in Pensylvanien.

Stenamma Westwoodi in Europa, bis jetzt noch nicht auf den südlichen Glicdern Europa's entdeckt.

Tomognathus sublaevis in Finnland. Smith führt im Cat. liese Art aus Frankreich an, welcher Fehler dadurch entstanden sein mag, dass sie von Nyl. in Form. Fr. besprochen wird, ohne dass aber der Autor Frankreich als Vaterland angibt.

Strongylognathus testaceus in der südlichen Hälfte Europa's bis zur Isothere des 19. Wgr. Smith führt im Cat. „Austria" als Vaterland an; das Kaiserthum Oesterreich kann er nicht meinen, da er Ungarn u. s, w, bei anderen Arten anführt, in Unter-oder Oberösterreich ist sie aber meines Wissens nicht gefunden worden.

Leptothorax acervorum in ganz Europa, doch noch nicht auf len südlichen Gliedern Furopa's.

Leptothorax Gredleri auf der Südhälfte von Europa bis zur Isothere des 19. Wgr., aber noch nicht auf der pyrenäischen Halbinsel gefunden.

Leptothorax clypeatus bisher blos bei Wien und Berlin entdeckt.

Leptothorax corticalis blos aus Deutschland (Nassau, Preussisch-Schlesien, Unterösterreich und Tirol) bekannt.

Leptothorax angustulus in Südfrankreich.

Leptothorax tirolensis in Tirol im Zillertbale.

Leptothorax affinis bei Wien im Prater, bei Chur in der Schweiz und in Bozen in Tirol. Leptothorax Nylanderi in der Südhälfte Europa's bis zur Isothere des 16 . Wgr. Leptothorax tuberum wahrscheinlich in ganz Europa, bisher in Schweden, Finnland, Deutschland, Ungarn und Frankreich gefunden.

Leptothorax unifasciatus in Europa, aber noch nicht auf der scandinavischen und pyrenäischen Halbinsel aufgefunden.

Leptothorax interruptus in der Süchialfte Europa's bis zur Isothere des $18^{\circ} 5 . \mathrm{W}^{\mathrm{g} g r}$. Tetramorium caespitum in ganz Europa.

Tetramorium simillimum in Grossbritannien. Smith citirt im Cat. „Austria," welcher er Leptothorax affinis irrigerweise als Synonym hinzuzählt.

? Tetramorium lippulum in Europa zerstreut.

Myrmica rubida in der Südhälfte Europa's bis zur Isothere des $1 \mathrm{~s}$. Wgr.

Myrmica laevinodis und ruginodis in Europa bis Sibirien.

Myrmica rugulosa, eine ziemlich seltene Art, welche wohl in ganz Europa verbreitet sein dürfte, aber im östlichen europäischen Russland, auf den britischen Inseln, sowie auf der pyrenäischen und Balkan-Halbinsel und auf den südlichen Inseln noch nicht gefunden wurde.

Myrmica sulcinodis in Mittel- und Nordeuropa, rerbreitet sich im nördlichen Asien bis Ostsibirien und in das nördliche China.

Myrmica lobicornis in Europa bis Ostsibirien.

Myrmica scabrinodis in ganz Europa.

Atta pallida in Sicilien bei Messina. 
Atta barbara im sadlichen Europa bis zur Isothere des 21. Wgr., in KleinAsien, auf Madeira und in Algier. Die Angabe Belke's, dass diese Art in Podolien lebt, dürfte wohl auf einer Verwechselung mit Atta structor beruhen. In meiner Abbandlung "Furmicina austriaca" ist bei dieser Art "Ungarn Kovats" citirt, doch scheint sie nicht in Ungarn vorzukommen.

Atta structor in der Südhailfte Europa's bis zur Isothere des 19. Wgr. In Asien auf Cypern und in Syrien; in Afrika auf Madeira.

Atta testaceo-pilosa in Sudeuropa bis zur Isothere des 22. Wgr. In Afrika in Algier. Smith führt im Cat. nebst anderen Standorten auch Austria und Dalmatia an, in Dalmatien findet sich wohl diese Art, aber nicht in Oesterreich.

Atta obsidiana im Kaukasus.

Atta striola auf der pyrenäischen und Balkan-IIalbinsel beiläufig bis zur Isothere des 23. Wgr.

Atta subterranea in der Südhälfte Europa's bis zur Isothere des 18 . Wgr.

Atta splendida in Griechenland und Sicilien.

Temnothorax recedens auf der Insel Zante und bei Beaucaire im südlichen Frankreich.

Pheidole pusilla in Andalusien, in Afrika auf Madeira. In Grossbritannien ist sie jedenfalls mit Waaren eingeführt.

Pheidole megacephala und Monomorium minutum in Südeuropa bis zur Isothere des 21. Wgr.

Monomorium mediterraneum in Europa blos bei Cadix, in Asien am rothen Meere.

Diplorhoptrum fugax in ganz Europa, in Asien auf der Insel Cypern, in Nordamerika bei New-York.

Diplorhoptrum Drewseni von Herrn Drewsen mit der Vaterlandsangabe „Italien erhalten.

Myrmecina Latreillei in Europa zerstreut.

Cremastogaster scutellaris und sordidula in Südeuropa bis zur Isothere des 21. $\mathrm{W}_{\mathrm{gr}}$. Erstere Art findet sich überdies in Nordamerika (Tennessee), in Afrika in Algier. (Smith gibt im Cat. für erstere Art auch Ungarn an, meint er vielleicht Fiume?) -

\section{Gäste und Sclaven der Ameisen.}

Seit langer Zeit schon haben die Coleopterologen ihr Augenmerk auf die Bauten der Ameisen geworfen, um in diesen, besonders im ersten Frühjahre, manchen seltenen und sonst unauffindbaren Käfer zu erhaschen. Die Staphylinen und Pselaphiden sind es vorzüglich, welche bei den Ameisen gefunden werden, aber auch viele andere Käfer, z. B. Scydmaenen, Cryptophagen, kleine Hysteriden, Lathidien, Ptenidium formicetorum, Monotoma conicicolle, Ptinus coarcticollis, Mycetocharis barbata. Auch andere Insecten verschiedener Ordnungen und Asseln, ja sogar Ameisen anderer Arten finden sich in ihren Colonien. Letztere sind daselbst oft in der Eigenschaft als Sclaven, indem sie als Larven oder Puppen von den Ameisen der betreffenden Colonien anderwärts geraubt, in ihre Nester getragen und aufgezogen werden, um als vollkommene Insecten Dienste zu leisten, da deren Räuber (Polyergus, Strongylognathus) wegen der eigenthümlichen Organisation der Oberkiefer zum Baue der Gänge in ihren Bauten untauglich sind und ihren Sclaven diese Geschäfte ïbertragen. 


\section{Literatur.}

Brullé Exp. Morée, Brullé: Expédition scientifique de Morée, Section des sriences physiques, T'ome III., Partie 1, 1832.

Curt. Brit. Ent., Curtis: Brifish Entomology VI. 1829.

Curt. Trans. Linn. Soc, Curtis: On the Genus Myrmica, and other indigenous Ants in den Transactions of the Limean Sociely of London. Vol. XXI,, 3. Theil 1854.

Dufour (Leon), Annales de la Sociéle entomologique de France V').

Fabr. Ent. Syst., Eabricius: Entomologia systematica emendata 1792-96.

Fabr. Mant. Ins., Fabricius: Mantis Insectorum.

Fabricius Systema Piezatorum 1804.

Fabr. Syst. ent., Fabricius: Systema entomologica.

Fonsc. Ann. Soc. ent. Fr., Boyer de Fonscolombe: Annales de la Société entomologique de France IV. 1846.

Först. Hym. Stud., Förster: Hymenopterologische Studien. 1. Heft, Aachen 1850.

Först. Verh. nat. V. Rheinl., Förster: Verhandlungen des naturhistorischen Tereines der Rheinlande. VII.

Gredl. Am. Tir., Gredler: Die Ameisen Tirols in dem VIII. Programme des Gymnasiums von Bozen. 1858.

Heer: Ueber die Hausameise Madeira's. An die Ziiricherische Jugend auf das Jahr 1852, von der naturforschenden Gesellschaft, LIV. Stïick.

Lepel. Hym., Lepeletier St. Fargeau: Histoire naturelle des Insectes Hymenoptères I. 1836.

Linné Faun. Suec., Linné Fauna Suecia. Ed. I. Holm 1746.

Linné Syst. nat., Linné Systema naturae 1735.

Los. Form. Piem., Losana: Saggio sopra le Formiche indigene del Piemonte in den Me. morie della Reale Accademia delle Scienze di Torino, XXXVII., 1834.

Ltr. Ess. Fourm. Fr., Latreille: Essai sur l' histoire des Fourmis de la France.

Ltr. Hist. Fourm., Latreille: Histoire naturelle des Fourmis, Paris 1802.

Ltr. Hist. nat. Crust. et Ins., Latreille: Histoire naturelle des C'rustacées et des Insectes.

Luc. Expl. alg., Lucas: Exploration scientifique de l'Algerie III.

Lund Lett. Hab. Fourm., Lund: Lettre sur les Habitudes de quelques Fourmis du Brésil, adressée à M. Audouin in den Annales des sciences naturelles, XXII. 1831.

Mayr: Deiträge aur Kenntniss der Ameisen in den Verhandlungen des zoologisch-botanischen Vereines in Wien, IU. 1853.

Mayr Beschr. einig. Am., Mayr: Beschreibungen einiger neuer Ameisen in den obigen Verhandlungen III.

Mayr Ein. n. Am., Mayr: Einige neue Ameisen in den obigen Verhandlungen II. 1852.

Mayr Form. austr., Mayr: Formicina austriaca, Beschreibung der bisher im österreichischen Kaiserstate aufgefundenen Ameisen nebst Hinzufïgung jener in Dentschland, in der Schweiz und in Italien vorkommenden Arten, in obigen Verhandlungen V. und bei Braumiller in Wien.

Mayr Ung. Am., Mayr: Ungarn's Ameisen in Programme der stailtischen Oberrealschul: zu Pest im Sehuljahre 1856/7.

Mayr Ueb. Abth. Myrm., Mayr: Ueber die Abtheilung der Myrmiciden und eine nene Gattung derselben in den Verhandlungen des zool. bot. Vereines III.

1) Die nicht gross gedruckten und nicht abgekinrzten Citate zeigen an, dass sie in vorliegender Arbelt nicht erwähnt sind.

Mayr. Formiciden. 
Nyl. Add, alt., Nylander: Additamentum alterum adnotationium in Monographiam formicarum borealium in den Actis Socielatis scientiarum Fennicae 1848.

Nyl. Add. adn., Nylander: Additamentum adnot. in Mon. form. bor. in obigen Actis 1846.

Nyl. Adn. Form. bor., Nylander: Adnolationes in Mon. form. hor. in obigen Actis 1846.

Nyl. Furm. Fr., Nylander: Synopsis des Formicides de France et d'Algérie in den Annales des sciences naturelles V., 4. Serie.

01. Encycl,, Olivier: Encyclopédie méthodique, Histoire naturelle.

Pz. Faun. germ., Panzer: F'auna germanica.

Rog. Beitr. Am. M. F., Roger: Beiträge zmr Kemutniss der Ameisen-Fauna der MittelmeerLänder in der Berliner entomologisehen Zeitschrift III. 1859.

Roger: Einiges über Ameisen in der Berliner entom. Zeitschrift I.

Schenck Beschr. nass. Am., Schenck: Beschreilumng nassauischer Ameisenarten in den Jahrbuichern des Vereines für Naturkunde im Herzogthume Nassau VIII.

Schenck; Systematische Lintheilung der nassauischen Ameisen nach Mayr in obigen Jahrbüchern XI. 1856.

Schilling: Bemerkumgen über die in Schlesien und der Grafschaft Glat\% vorkommenden Arten der Ameisen in der Uebersicht der Arbeiten und Verinderungen der schlesischen Gesellschaft für vaterlindische Cultur im Jahre 1838, Breslau.

Smith Brit. Form., Smilh: Essay on the Genera and Species of British Formicidae in den Transactions of the Entomological Society Vol. WI., N. S. Part. 3.

Smith Cat., Smith: Calalogue of Hymenopterous Insects in the Collection of the British Museum, Part. VI. Formicidae 1858.

Smith Notes on the Habits of various Species of British Ants in den Transactions of the Entomological Socicty Vol. III. N. S.

Smith Revis. Brit. Form., Smith: Revision of an Essay on the British Furmiridae in obigen Transactions IV.

Spin. Ins. Lig, Spinola: Insectorum Liguriae Species novae aut rariores Tom. I. Fasc. 4. Genua 1808.

Spin. Mem. Accad. Scienz. Tor., Spinola: Comple rendu des Hymenoptères inedits provenants du voyage entomologique de M. Ghiliani dans le Para en 1846 in den Memorie della Reale Accademia delle Scienze di Torino II. Serie, XIII.

Westw, Intr. Class. Ins. II.

Westw. Ann. Mag, nat. Hist, Westwood: Observations on the Genus Typlilopone with Descriptions of several exotic species of Ants in den Annals and magazine of natural history VI. 1841. 


\section{Erste Tabelle}

ZuI

Bestimmung der Subfamilie. 



\section{Fam. Formicidac.}

Fühler 10-13 gliederig, gebrochen, deren erstes Glied (Schaft) durch Lange meist ausgezeichnet. Hinterleib sechs-, bei den Männchen siebengliederig, lessen crstes Segment (Stielchen) vom übrigen Hinterleibe abgeschnürt und oben knotenförmig oder mit eiuer Schuppe, oft auch das zweite Segment abgeschnürt uml knotenförmig. Schenkelring einfach. Erstes Tarsenglied stielförmig. Die Flügel sind in der Ruhe nicht zusammengefaltet, haben vier Längsrippen am Grunde, keine oder nur eine Discoidalzelle und eine oder zwei geschlossene Cubitalzellen. Die Colonien bestehen zu gewisser Jahreszeit aus geflügelten Männchen und Weibchen, sowie aus ungeflügelten Arbeitern, selten noch Soldaten.

1 Stielehen eingliederig. . . . . . . . . . . . . . . 2

- zweigliederig. Myrmicidae.

2 Der cigentliche Hinterleib zwischen dem ersten und zweiten Segmente nicht eingeschnürt.

Formicidac.

Der Hinterleib zwischen dem ersten und zweiten Segmente eingeschnürt.

Poneridae. 



\section{Zweite Tabelle}

zIII

Bestimmung der Gattung. 



\title{
I. Subfam. Formicidae.
}

\author{
Arbeiter.
}

1 Schild- und Fühlergrube von einander entfernt und getremnt; die 12gliederigen Fühler entspringen nicht am vorderen Ende der Stirnleisten und sind vom Rande des Clypeus entfernt (Fig. 6): Thorax oben bogenförmig gekriimmt, zwischen dem Meso- und Metanotum nicht eingeschnïrt (Fig. 10); Stielchen mit aufrechter Schuppe; Punctangen fehlen . . . . . . . . . . . - _ - - - gehen ohue Grenze in einander über; die Fühler entspringen an vorderen Ende der Stirnleisten am Rande des Clypeus ...... .

2 Die Seitenrïinder des trapezförmigen Clypeus divergiren nach vorne; Stirnleisten S-förnig gekrümmt (Fig. 6); Stirnfeld nicht scharf abgegrenzt, etwa doppelt so breit als lang; Schuppe des Stielchens vorne und hinten fast gleichmässig schwach gewölbt.

1. Gatt. Camponotus n. g. - _ _ - des Clypeus parallel, nur an den Vorderecken seitlich etwas erweitert; Stimfeld nicht oder sehr undeutlich ausgeprägt; Sehuppe des Stielchens vorne gewöllbt, hinten flach.

2. Gatt. Colobopsis n. g.

3 Der dreieckige, hinten fast halbkreisförmig abgerundete Clypeus setzt sich zwischen den Fühlergelenken nach hinten fort (Fig. 16); Sporne kammförmig . . . . . . . . . . . . . .

Der Clypens setzt sich nicht zwischen den Fühlergelenken fort; der Thorax ist oben zwischen dem Meso- und Metanotum meist eingeschnürt . . .

4 Die wagrechte Basalflïche des grossen Metanotum hinten durch eine scharfe beiderseits mit einem Zahne endende Kante von der stark ausgehöhlten, senkrechten abschüssigen Fläche getrennt; Clypeus in der Mitte seines Vorderrandes eingedrïckt; Stielchen mit sehr dicker, keilförmiger, stark nach vorne geneigter Schuppe.

4. Gatt. Ilypoclinea. Mayr.

Metanotum gewölbt, ungezähnt, dessen abschiissige Flïehe eben . . . . 5

5 Thorax oben bogenförmig gekrümmt, ohne Einschnürung; Clypeus (Fig. 16) in der Mitte des Vorderrandes ohne Einschnitt, bei den Kiefergelenken ohrförmig aufgebogen; Punctaugen vorhanden; Stimrinne seicht; Stielchen mit aufrechter, ovaler, oben abgerundeter Schuppe.

3. Gatt. Liometopum n. g.

- - zwischen dem Meso- und Metanotum eingedrickt; Clypeus in der Mitte des Vorderrandes ziemlich tief und schmal eingeschnitten, seitlich nicht aufgebogen; Punctaugen und Stirnrinne fehlen; Stielehen viereckig, flach, vom nach vorne erweiterten Hinterleibe bedeckt, nach vorne etwas ansteigend und in eine quere, abgerundete, ziemlich dicke Leiste endigend (Fig. 17 und 18).

5. Gatt. Tapinoma. Först.

6 Ol,erkiefer (wie bei den meisten Ameisen) flachgedriickt, am Ende mit gezithntem Kanrande. . . . . . . . . . . . . .

- - cylindrisch, gekriimmt, sehr schmal, am Ende zugespitzt, ohne Kaurand (Fig. 22); Stirnfeld scharf abgegrenzt; Punctaugen vorhanden; Metanotum stark buckelförmig erhöht; Stielchen mit einer dicken, ovalen, hohen und aufrechten Schuppe.

8. Gatt. Polyergus. Ltr.

7 Fühler 11 gliederig. . . . . . . . . . . . . . . . s

- 12 gliederig . . . . . . . . . . . . . 9

8 Punctangen vorhanden; Thorax selır schmal und zart; Mesothorax zusammengezogen; zwischen dem Meso- und Metanotum ist eine tiefe Furche, das 
buckelig erhöhte Metanotum trïgt zwei spitze nach aufwärts gerichtete Zähne; Stielchen mit einer etwas nach vorne geneigten, aufrechten, oben zweizähnigen und tief ausgeschnittenen Schuppe. 6. Gatt. Acantholepis n. g.

Punctangen fehlen; Thorax oben sehr wenig zwischen dem Meso- und Metanotum eingezogen, etwas uneben bogenförmig von vorne nach hinten; Metanotuu ungezalint; Stielehen mit einer schief nach oben und vorne gerichteten, schmalen, oben abgerundeten Schuppe. (Eine der kleinsten Ameisen-Gattungen.)

7. Gatt. Plagiolepis n. g.

9 Die ersteren Glieder der Geissel sind lïnger als die letzteren, mit Ausnahme des Endgliedes (Fig. 21 und 23); Punctaugen dentlich; Stirnfeld scharf abgegrenzt

Das zweite, dritte, vierte und fünfte Geisselglied kürzer und kleiner als die letzteren Glieder; Punctangen undeutlich oder fehlend; Stirnfeld nicht scharf ausgeprägt, fast doppelt so breit als lang . . . . . . . . . .

10 Das vierte Glied der Kiefertaster ist fast doppelt so lang als das fünfte Glied; Stirnleisten fast parallel, deren Rand aussen concav; Stielchen oben mit einem kugeligen Knoten oder mit einer dicken Schuppe.

9. Gatt. Cataglyphis. Först. ist nur wenig länger als das fünfte Glied; Stirnleisten nach hinten divergirend, deren Rand aussen schwach convex; Stielchen mit einer grossen aufrechten Schuppe.

10. Gatt. Formica. L.

11 Stielchen mit einer senkrechten oder fast senkrechten viereckigen schmalen Schuppe; Hinterleib nicht nach vorne verlängert; Vorderrand des Clypeus nicht ausgerandet; Punctaugen sehr klein und undeutlich.

11. Gatt. Lasius. Fabr. _- _ - _ schief nach oben und vorne gerichteten viereckigen Schuppe; der hinten etwas spitzig zulaufende Hinterleib ist nach oben und vorne erweitert und stark gewölbt, auf der hinteren, oberen Fläche der Schuppe aufliegend; Vorderrand des Clypeus in der Mitte bis zur. Schildgrube seicht ausgerandet; Stimrinne und Punctaugen fehlen. 12. Gatt. Prenolepis n. g.

\section{Weibchen.}

1 Schild- und Fühlergrube getrennt; die 12 gliederigen Fühler entspringen nicht am vorderen Ende der Stirnleisten, sie sind vom Rande des Clypeus entfernt / 2

__ _ - - gehen in einander ohne Grenze über; die Fühler entspringen am vorderen Ende der Stirnleisten, am Rande oder an den Hinterecken des Clypeus. . . . . . . . . . . . . . . . .

2 Die Seitenrïnder des trapezförmigen Clypeus divergiren nach vorne; Stirnleisten S-förmig; Stirnfeld nicht scharf abgegrenzt, etwa doppelt so breit als lang; Schuppe des Stielchens vorne und hinten fast gleichmässig schwach gewölbt; Flügel mit einer Cubital- und einer Discoidalzelle.

1. Gatt. Camponotus n. g. __ - - des Clypeus parallel, blos die Vorderecken seitlich etwas erweitert; Stirnfeld nicht ausgeprägt; Schuppe des Stielchens vorne ziemlich gewölbt, hinten flach.

2. Gatt. Colobopsis n. g.

3 Der dreieckige, hinten fast halbkreisförmig abgerundete Clypeus setzt sich zwischen den Fühlergelenken nach hinten fort; Sporne kammförmig . . .

Der Clypeus setzt sich nicht zwischen den Fühlergelenken fort . . . . . .

4 Metanotum mit zwei starken, kurzen Zähnen, abschüssige Fläche desselben stark ausgehöhlt; Clypeus in der Mitte des Vorderrandes mit einem Eindrucke; Stirnrinne seicht und fein; Stielchen mit einer sehr dicken, keilförmigen, stark nach vorne geneigten Schuppe; Flügel mit zwei Cubitalzellen.

4. Gatt. IIypoclinea. Mayr.

Clypeus in der Mitte des Vorderrandes ohne Einschnitt, bei den Kiefergelenken ohrförmig aufgebogen; Stirnrinne sehr tief eingedrückt; Stielchen mit einer aufrechten, ovalen, oben scharf bogenförmig ausgeschnittenen Schuppe; Flïgel mit zwei Cubitalzellen.

3. Gatt. Liometopum n. g. se- ziemlich tief und schmal eingeschnitten, 
vom nach vorne gezogenen Hinterleibe bedeckt, flach, nach vome etwas ansteigend und in eine quere, abgerundete, ziemlich dicke Leiste endigend; Flügel mit einer Cubitalzelle.

5. Gatt. Tapinoma. Först.

Oberkiefer flachgedriickt, am Ende mit gezähntem Kaurande . . . . . . . cylindrisch, gekriimmt, sehr schmal, am Ende zugespitzt, ohne Kaurand; Stirnfeld scharf abgegrenzt; Stielehen mit einer dicken, ovalen, hohen und aufrechten Schuppe; Fliigel mit einer Cubital- und einer Discoidalzelle.

8. Gatt. 'olyergus. Ltr.

7 Fühler 11 gliederig; Stielchen mit einer sehr stark nach vorne geneigten, keilförmigen, vom Hinterleibe oben bedeckten Schuppe . . . . . . . . . .

- 12 gliederig; Stielchen mit einer aufrechten oder nur wenig nach vorne geneigten Schuppe. . . . . . . . . . . . . . . . . . .

8 Die ersteren Geisselglieder sind länger als die letzteren, mit Ausnahme des letzten; Schuppe oben zweiztihnig; Augen etwas hinter der Mitte des Kopfes.

6. Gatt. Acantholepis n. g.

Das zweite, dritte, vierte und fünfte Geisselglied kürzer als die letzteren Glieder der Geissel; Schuppe oben abgerumdet, ungezähnt; Augen vor der Mitte des Kopfes; Fliigel mit einer Cubitalzelle.

7. Gatt. Plagiolepis n. g.

9) Stirnfeld nicht seharf abgegrenzt; zweites bis vorletztes Geisselglied an Länge einander gleich, die letzteren dicker; Augen etwas hinter der Mitte des Kopfes.

11. Gatt. Lasius. Fabr.

_- scharf abgesetzt; die ersteren Glieder der Geissel länger als die letzteren

10 Das vierte Kiefertasterglied ist doppelt so lang als das fuinfte Glied; Rand der Stiruleisten aussen coneav; Stielchen oben mit einem kugeligen Knoten oder mit einer dicken herzförmigen Schuppe; die Flügel reichen nur bis zum Ende des Hinterleibes, deren Discoidalzelle ist klein oder fehlt.

9. Gatt. Cataglyphis. Först.

__ _ _ _ ist wenig länger als das fünfte; Rand der Stimleisten aussen convex; Stielchen oben mit einer Schuppe; die Fligel überragen bedeutend den Hinterleib, deren Discoidalzelle ist gross oder sie fehlt manchmal.

10. Gatt. Formica. Linné.

\section{Männchen.}

1 Fliigel mit zwei Cuhitalzellen; der ungekielte, dreieckige, hinten abgerundete Clypeus setzt sich zwischen den Fûhlergelenken fort; Schaft der 13 gliederigen Fühler nur so lang, als die zwei bis drei ersten Geisselglieder. . .

Flügel mit einer Cubitalzelle

2 Stielchen mit einer aufrechten, oben ausgerandeten Schuppe; die sehr grossen Genitalien nehmen das hintere Drittheil des Hinterleibes ein, die sehr grossen, halbkreisformigen Schuppen der Genitalien sind unten in eine abgerundete, messerförmige Platte verlängert, die äusseren Genitalklappen sind am Grunde breit, gegen das Ende allmählich verschmälert und am Ende abgerundet.

3. Gatt. Liometopum n. g.

_- knotenförmig, ohne Schuppe; Genitalien klein, äussere Genitalklappen fast halbkreisförmig.

4. Gatt. IIy poclinea. Mayr.

3 Fiihler 12 gliederig, entspringen an den Hinterecken des Clypeus; Oberkiefer dreizähnig; das Mesonotum überwölbt das kleine Pronotum; Stielchen mit einer schief nach vorne und oben geneigten Schuppe; äussere Genitalklappen fast kreisförmig, am Ende in einen stumpfen Zahn auslaufend.

7. Gatt. PIngiolep is $11 . \mathrm{g}$.

- 13 gliederig.

\pm Oberkiefer cylindrisch, selı dünn, am Ende spitzig, ohne Kaurand; Clypeus dreieckig, hinten stark abgerundet, gewölbt; Schuppe des Stielchens aufrecht, dick, viereckig; äussere Genitalklappen dreieckig, doppelt so lang als am Grunde breit, am Ende abgerundet. 8. Gatt. Polyergus. Ltr.

5 Ventralplatte in der Mitte bis zum Grunde ausgeschnitten, äussere Genitalklappen ziemlich dick, löffelförmig, mit der Convexität nach aussen; der 
dreieckige, hinten abgerundete Clypens setzt sich etwas zwisehen den Fiihlergelenken fort; Stirnfeld und Stimrime fehlen; Stielchen dick, oben schict abgeflacht und abgerundet, von der Seite gesehen fast rhomboidisch.

5. Gatt. Tapinoma. Först.

Ventralplatte in der Mitte nicht ausgesehnitten; der viereekige Clypeus setzt sielı nicht zwischen den Fühlergelenken fort; Stielchen mit einer aufreehten Sehuppe . . . . . . . . . . . . .

6 Genitalien sehr klein; Stimfeld nicht scharf ausgeprägt, heilïufig doppelt so breit als lang. . . . . . . . . . . . . . . . . . 7

_- gross; Stimfeld scharf abgegrenzt, beilinfig so lang als breit . . . . 8

7 Stirnleisten lang, S-förmig gekrümmt; die Fühler entspringen nicht an den Hinterecken des Clypens; ¿̈ussere Genitalklappen dornförmig.

1. Gatt. Camponotus n. g.

- - kurz, hinten etwas divergirend; die Fühler entspringen an den Hinterecken des Clypeus; äussere Genitalklappen flach, doppelt so lang als am Grunde breit, gegen das Ende versehmillert und daselbst halbkreisförmig abgerundet.

11. Gatt. Lasius. Fabr.

8 Dic Penicilli fehlen, die äusseren Genitalklappen haben an der Inmenseite einen löffelförmigen Anhang; Hinterleib oben und unten gleichförmig gewölbt; die Flügel reichen bis zum Ende des Körpers, die Discoidalzelle ist sehr klein oder fehlt. Das erste Geisselglied ist so lang als das zweite; Thorax seitlich zusammengedrüekt und ziemlich gleichbreit; Pronotum in der Mitte von vorue unten nach hinten oben etwas concav.

9. Gatt. Cataglyphis. Först.

- _ - sind vorhanden, die äusseren Genitalklappen sind messerförmig und haben keinen Anhang; Hinterleib oben ziemlich flachgedrückt; die Fliigel iberragen den Hinterleib, deren Discoitlalzelle ist gross (selten fehlt sie). Das erste Geisselglied ist $\mathrm{um}$ ein Drittheil kiuzer als das zweite Glied; Thorax seitlich in der Mitte etwas erweitert; Pronotum in der Mitte von vorne unten nach hinten oben etwas convex. 10. Gatt. Formica. Linné.

\section{Subfam. Poneridac.}

$$
\text { 후 }
$$

1 Fühler 11gliederig; die Netzaugen fehlen (die Punctaugen fehlen allen Poneriden-Arbeitern); Kopf viereckig, Oberkiefer schmal; Hinterleib am Ende mit einem halbkreisförmigen Eindrucke, beiderseits mit kurzen Zähnchen. $\Varangle$.

13. Gatt. Typhlopone. Westw.

- 12 gliederig (beim $\delta^{\star} 13$ gliederig). .......... 2

2 Die Oberkiefer entspringen aus der Mitte des Vorderrandes des Kopfes, ihre Gelenke berïhren sich fast, sie sind etwas flachgedrückt, gerade nach vorne gestreckt, lang und erst am Ende stark nach innen gebogen und mit zwei bis drei Zïhnen versehen. $\Varangle$ 15. Gatt. Anochetus u. g.

Die gekrümmten Oberkiefer entspringen an den Vorderecken des viereckigen

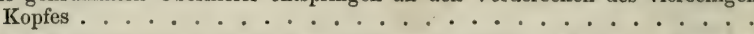

3 Die Oberkiefer sind breit, flachgedrückt, mit gez:̈ihntem Kaurande (bein $ð$ sind sie schmal, am Ende abgerundet und ungezilint); die beim Arbeiter äusserst kleinen, beim Weibchen und Mänuchen grossen Netzaugen sitzen am Vorderkopfe; Clypeus vorne ungezähnt; das Sticlchen mit der Schuppe ist nicht mit seiner ganzen hinteren Fliiche am Hinterleibe angewachsen. ช $\subsetneq \sigma^{x}$.

16. Gatt. Ponera. Ltr.

- - - - sind schmal, ohne Kaurand, deren ganzer Innenrand ist gezïhnt; die äusserst kleinen Netzaugen sitzen am Hinterkopfe; der Clypeus ist am ganzen Vorderrande gezïhnt; das Stielchen hat keine Seluppe, es ist mit seiner ganzen Hinterfläche an den Hinterleib angewachsen. $\not$.

14. Gatt. Stigmatomma. Rog. 


\title{
III. Subfam. Myrunicidae.
}

\author{
Arbeiter.
}

1 Stielchen an der Oberseite rles herzförmigen, hinten spitzigen Ilinterleibes befestigt; Kiefertaster fünf-, Lippentaster dreigliederig ; Fiiller 11 gliederig; erstes Stielchenglied trapezfïmig (Fig. 36 и. 37). 29. Gatt. Cremastogaster. Lund. - - an das Vorderende des eiförmigen Hinterleibes befestigt.

2 Oberkiefer sehr sehmal, cylindrisch, etwas gekriimmt, in eine Spitze auslaufend, ohne Kaurand; Kopf rechteckig, hinten tief bogenförmig ausgeschnitten; Kiefertaster vier-, Lippentaster dreigliederig.

19. Gatt. Strongylognathus. Mayr.

_- breit, flachgedrickt, mit meist geziihtem Kaurande. . . . . . . . . 3

3 Kenle der 10 gliederigen Fiihler sehr gress, zweigliederig (Fig. 33); Clypens mit zwei Lä̉ngsleisten; Kiefer - und Lippentaster zweigliederig; Metanotum unbewehrt.

27. Gatt. Diplorhoptrum. Mayr.

- nicht zweigliederig, Fïhler 11-12gliederig

4 Zweites Stielchenglied unten mit einem langen nach abwïrts und vorne gerichteten Dorne; Fïhler 11 gliederig . . . . . . . . . . . 5

- _ ohne Dorn; Fühler 11- oder 12gliederig . . . . . . . 6

5 Kaurand der Oberkiefer gezähnt; Kiefertaster vier-, Lippentaster dreigliederig; Clypeus gross; Stirnleisten kurz; Fühlerkeule dreigliederig (Fig. 25).

17. Gatt. Stenamma. Westw. schneidig, ungeziihnt; Kiefertaster fünf-, Lippentaster dreigliederig; Clypeus klein; die Stimleisten reichen fast bis zum Hinterhaupte; Fühlerkeule viergliederig.

18. Gatt. Tomognathus n. g.

(i) Erstes Stielchenglied viereckig. Der undeutlich gezïhnte Kaurand der Oberkiefer winkelig, so dass bei geschlossenen Kiefern zwischen diesen und dem Clypeus ein Dreieck frei bleibt; der kurze Clypeus mit zwei vorne in stumpfe Zähne endenden Längsleisten; Fühler I2 gliederig, deren Keulc dreigliederig (Fig. 34); Augen vor der Mitte des Kopfes; Thorax oben ohme Einsehnitt; Metanotum hinten mit zwei Dornen und mit zwei kleinen Zähnchen am Vorderrande.

28. Gatt. Myrmecina. Curt.

_- _ vorne cylindrisch, hinten verdickt . . . . . . . . . . 7

7 Die drei letzten Glieder der 12 gliederigen Fühler sind entschieden kürzer als die übrigen Geisselglienter * * * * * * lïnger als - der Geissel, welche die Keule bilden, sind so lang ode

8 Kiefertaster vier-bis fïnfgliederig, Lippentaster dreigliederig; Stimfeld tief eingedrïckt, hinten abgerundet (Fig. 28); Thorax oben zwischen dem Mesound Metanotum zusammengezogen, Pro- und Mesonotum mehr oder weniger halbkugelig; Sporne einfach.

23. Gatt. Atta. Fabr.

- - sechsgliederig, Lippentaster viergliederig; Stimfeld hinten spitz; Thorax oben zwischen dem Meso - und Metanotum mit oder olne Einschnitt, vor diesem ziemlich flach; Schenkel keulenförmig; Sporne kammförmig.

22. Gatt. Myrmica. Ltr

9 Metanotum vollkommen umbewehrt; Kiefertaster ein- oder zweigliederig, Lippentaster zweigliederig; Clypeus vorne vorgezogen, dessen Vorderrum von den Oberkiefern abstehend, in der Mitte mit einer Längsfurche; letztes Geisselglied lïnger als die zwei vorletzten zusammen (Fig. 32).

26. Gatt. Monomorium. Mayr.

_- mit zwei Zähnen oder Dornen

10 Die Keule der Geissel besteht aus drei sehr langen Gliedern, das neunte Geisselglied ist melur als doppelt so lang als das achte, das Endglied ist nur wenig lïnger als das vorletzte (Fig. 31); Oberkiefer sehr breit, deren Kaurand (beim Arbeiter) durchaus gezähnt oder (beim Soldaten) schneidig; Kiefer- und Lippentaster zweigliederig; Thorax zwischen dem Meso- und Metanotum stark eingeschnürt. 
Die Kenle der Geissel besteht aus drei Gliedern, das neunte Geisselglied ist nicht doppelt so lang als das achte, das Endglied ist mehr als doppelt so lang als das vorletzte

11 Thorax zwischen dem Meso- und Metanotum nicht oder wenig eingeschnürt; Clypeus ohne leistenartigem Mittelkiele; Keule der Fiihler dick; Stirnfeld entweder undeutlich oder deutlich ausgeprïgt und eben........

etwas bogig gekriimmten Dornen: Clypeus wenig gewölbt, längs der Mitte mit einem leistenartigen Kicle; Fiihlerkeule dïm; Stirnleisten schwach S-förmig; Stirnfeld besonders in der Mitte stark eingedrückt, aber nicht scharf abgegrenzt; Oberkiefer füinfzïhnig; Schenkel in der Mitte am dicksten; Sporne einfach.

24. Gatt. Temnothorax n. g.

12 Hinterer Rand des Clypens zwischen der Stirnleiste und dem Kiefergelenke aufgebogen und als erhabene Leiste die Fühlergrube vorne begrenzend, vorderer Rand des Clypeus nicht aufgebogen; Kiefertaster vier-, Lippentaster dreigliederig; Pronotum vorne beiderseits stumpfeckig; Thorax kurz, hoch, zwischen dem Meso- und Metanotum ohne Einschniirung; obere Fläche der Vorderhälfte des ersten Stielchen liedes concav von vorne nach hinten; Fühler 12 gliederig.

21. Gatt. Tetramorium. Mayr.

voricher aufgebogen, Kiefertaster fiinf-, Lippentaster. abgerundet; 'Thorax mehr als doppelt so lang als hoch, zwischen dem Mesonnd Metanotum nicht oder schwach eingeschnürt; obere Fläche der Vorderhälfte des ersten Stielchengliedes fast gerade vou vorne nach hinten; Fuihler 11- oder 12 gliederig.

20. Gatt, Leptothorax. Mayr.

\section{Weibelien $\%$.}

1 Stielchen an der Oberseite des hinten spitzigen, unten stärker als oben gewölbten Hinterleibes befestigt; Fühler 11gliederig; erstes Stielchenglied trapezförmig; Flügel mit einer Cubitalzelle, die Querrippe verbindet sich mit dem äusseren Cubitalaste. 29. Gatt. Cremastogaster. Lund.

_- an das vordere Ende des eiförmigen Hinterleibes befestigt. . . . . 2

2 Oberkiefer sehr schmal, cylindrisch, gekrümmt, in eine Spitze endigend, ohne Kaurand; Kopf rechteckig, hinten tief bogenförmig ausgeschnitten; Flügel mit einer Cubitalzelle, die Querrippe verbindet sich mit der Cubitalrippe an der Theilungsstelle.

19. Gatt. Strongylognathus. Mayr.

- flachgedrückt, mit meist gezähntem Kaurande. . . . . . . . . . 3

3 Kenle der 1 Igliederigen Fühler zweigliederig, sehr gross; Clypeus mit zwei Längsleisten; Metanotum unbewehrt; Flügel mit einer Cubitalzelle; die Querrippe verbindet sich mit dem äusseren Cubitalaste (Fig. 3).

27. Gatt. Diplorhoptrum. Mayr. - - - 11-12 gliederigen Fühler nicht zweigliederig ........ 4

4 Kaurand der Oberkiefer schneidig, blos vorne mit zwei Zähnen bewaftinet; Keule der 12 gliederigen Fühler halb so lang als die Geissel; Thorax niedrig, oben flachgedrückt; zweites Stielchenglied seitlich kegelartig erweitert; Flïgel mit zwei Cubitalzellen.

25. Gatt. Pheidule. Westw.

5 Fühler 11gliederig, deren Geissel verdickt sich allmählich zu einer Keule; zweites Stielchenglied unten mit einem etwas nach vorne gerichteten Dorne; Kaurand der Oberkiefer gezähnt; Flügel mit einer Cubitalzelle, die Querrippe verbindet sich mit der Cubitalrippe an der Theilungsstelle.

17. Gatt. Stenamma. Westw.

- - 11-12 gliederig; zweites Stielchenglied ohne Dorn ........ 6 
6 Erstes Stielchenglied viereckig; der kurze Clypeus mit zwei vorne in stumpfe Zähne endenden Längsleisten; Fühler 12 gliederig; Augen vor der Mitte des Kopfes; Metanotum mit zwei nach hinten gerichteten Dornen; Flügel mit einer Cubitalzelle, die Querrippe verbindet sich mit dem äusseren Cubitalaste (Fig. 35).

28. Gatt. Myrmecina. Curt.

- - - vorne eylindriseh, hinten verdickt . . . . . . . . . . .

7 Metanotum ohne Höcker oder Zähne; Thorax höher als breit; Mesonotum kantig dreiseitig; Keule der 12 gliederigen Fühler halb so lang als die ganze Geíssel; Clypeus vorne vorgezogen, mit einer Längsgrube in der Mitte.

26. Gatt. Monomorium. Mayr.

_- mit Dornen, Höckern oder Zähnen; Mesonotum nicht kantig; Clypeus nicht vorgezogen.

8 Flügel mit zwei Cubitalzellen (Fig. 4); Sirnfeld hinten abgerundet.

23. Gatt. Atta. Fabr.

— - mit einer Cubitalzelle; Stirnfeld hinten nicht abgerundet. . . . . . . 9

9 Flügel mit halbgetheilter Cubitalzelle (Fig. 5); Sporen kammförmig.

22. Gatt. Myrmica. Ltr.

- mit ungetheilter Cubitalzelle; Sporen einfach .

. . .

10 Grosse Weibchen (zwei- bis dreimal so gross als die Arbeiter); hinterer Rand des Clypeus zwischen der Stirnleiste und dem Kiefergelenke als erhabene Leiste die Fühlergrube vorne begrenzend; Fühler 12 gliederig.

21. Gatt. Tetramorium. Mayx.

Weibchen unbedeutend grösser als die Arbeiter; hinterer Rand des Clypeus zwischen der Stirnleiste und dem Oberkiefergelenke nicht aufgebogen; Fühler 11-12 gliederig; Thorax ziemlich hoch, seitlich gedrückt.

20. Gatt. Leptothorax. Mayr.

\section{Männchen.}

1 Mesonotum mit den zwei convergirenden, tief eingedrückten, etwas hinter der Mitte des Mesonotum sich vereinigenden und als Furche bis zum Hinterrande des Mesonotum ziehenden Linien . . . . . . . . . . . . _

2 Flügel mit halbgetheilter Cubitalzelle (Fig. 5); Oberkiefer gezähnt; erstes Geisselglied der 13 gliederigen Fühler kürzer als das zweite Glied. 22. Gatt. Myrmica. Ltr. mit ungetheilter Cubitalzelle

3 Die Querrippe der Flügel verbindet sich mit der Cubitalrippe an der Theilungsstelle (Fig. 1).

verbindet sich mit dem äusseren Cubitalaste (Fig. 35);

Oberkiefer ziemlich schmal, dreizähnig, unter der zweilappigen Oberlippe verborgen; Schaft der 13 gliederigen Fühler etwas kürzer als die zwei ersten Geisselglieder.

28. Gatt. Myrmecina. Curt.

4 Fühler $12-13$ gliederig . . 10 gliederig, deren Schaft kürzer als das lange zweite Geisselglied (Fig. 27) . . . . . . . . . . . . . . . . . .

lypeus gewölbt, nicht gekielt; Stirnfeld nicht oder undeutlich ausgeprägt;

Metanotum nicht verlängert.

20. Gatt. Leptothorax. Mayr.

___ gekielt; Stirnfeld schmal und tief; Metanotum lang; Fühler 13 gliederig.

17. Gatt. Stenamma. Westw.

6 Oberkiefer flach, deren Kaurand gezähnt.

21. Gatt. Tetramorinm. Mayr. - _ sehr schmal, cylindrisch, am Ende zugespitzt, ohne Kaurand.

19. Gatt. Strongylognathus. Mayr.

7 Flügel mit einer Cubitalzelle . . . . . . . . . . . . . . . 8

-_ - zwei Cubitalzellen (Fig. 4) . . . . . . . . . . . . . . . . . . 10

8 Die Querrippe der Flügel verbindet sich blos mit dem äusseren Cubitalaste

(Fig. 3); Fühler 12 gliederig, erstes Geisselglied kugelig, Schaft sehr kurz.

___ _ - mit der Cubitalrippe an der Theilungsstelle;

Fühler 13 gliederig, erstes Geisselglied nicht kugelig; Metanotum ungezähnt,

äussere Genitalklappen gross, zangenförmig. 26. Gatt. Monomorium. Mayr'). 
9 Stielchen an der Oberseite des hinten spitzigen, unten stärker als oben gewölbten Hinterleibes befestigt.

29. Gatt. Cremastogaster. Lund. - - wie bei allen anderen Ameisen an das vordere Ende des eiförmigen Hinterleibes befestigt; Fühler 12 gliederig. 27. Gatt. Diplorhoptrum. Mayr.

10 Erstes Geisselglied kugelig, die anderen Glieder eylindrisch; die äusseren Genitalklappen messerförmig, am Ende schief abgeschnitten; Ventralplatte stark nach vorne gerïickt. 25 . Gatt. Pheidole. Westw. Alle Geisselglieder cylindrisch; die äusseren Genitalklappen dreieckig, am Ende abgerundet.

23. Gatt. Atta, Fabr.

1) Die Charakteristik dieser Gattung ist von einer auf Maleira lehenden nenen Art entlehnt. 


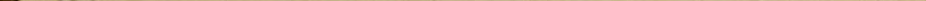


